This is the pre-peer reviewed version of the following article:

Roesch R., Faber T., Von Hauff E., Brown T.M., Lira-Cantu M., Hoppe H.. Procedures and practices for evaluating thin-film solar cell stability. Advanced Energy Materials, (2015). 5. 1501407: - . 10.1002/aenm.201501407,

which has been published in final form at https: //dx.doi.org/10.1002/aenm.201501407. This article may be used for non-commercial purposes in accordance with Wiley Terms and Conditions for Use of Self-Archived Versions. 


\section{Procedures and Practices for Evaluating Thin-Film Solar Cell Stability}

Roland Roesch, Tobias Faber, Elizabeth von Hauff, Thomas M. Brown, Monica Lira-Cantu, Harald Hoppe*

Dr. R. Roesch, T. Faber, Dr. H. Hoppe

Institute of Physics, Technische Universität Ilmenau, 98693 Ilmenau, Germany

E-mail: harald.hoppe@tu-ilmenau.de

Dr. H. Hoppe

Institute of Organic Chemistry and Macromolecular Chemistry, Friedrich Schiller University, 07743 Jena, Germany

Dr. E. von Hauff

Department of Physics and Astronomy, Vrije Universiteit Amsterdam, 1081 Amsterdam, The Netherlands

Dr. T. M. Brown

CHOSE, Department of Electronics Engineering, University of Rome "Tor Vergata", 00133

Rome, Italy

Dr. Monica Lira Cantu

Catalan Institute of Nanoscience and Nanotechnology (ICN2), Nanostructured Materials for Photovoltaic Energy Group, 08193 Bellaterra, Barcelona, Spain

Consejo Superior de Investigaciones Científicas (CSIC), 28006 Madrid, Spain

Keywords: thin-film solar cells, stability testing protocols, burn-in, long-term degradation, operational stability
Abstract
During the last few decades - in some cases only a few years -novel thin-film photovoltaic (PV) technologies such as dye-sensitized solar cells (DSSC), organic solar cells (OPV) and lately perovskite-based solar cells (PSC) have been growing in maturity with respect to device performance and, at least similarly important, device stability. Together with new material systems, novel device architectures are also introduced. Both parameters will have an effect on the overall device stability. In order to improve the understanding of degradation effects and how they can be prevented, stress testing under different conditions is commonly applied. By careful combination of stress factors and thorough analysis of photovoltaic parameter decaying curves, an understanding of the underlying degradation pathways can be gained. By the help of standardized and accelerated stress tests as described in the ISOS-protocols, 
statements concerning application lifetimes can finally be made and compared among different labs. Once a photovoltaic technology has proven long lasting durability, the ultimate barrier for entering the commercial market are the IEC tests, taking a deeper look on overall safety and reliability instead of durability. In this article, the most prominent stress tests are reviewed, discussed and extended with respect to learning the most about photovoltaic device stability.

\section{Introduction}

During the last two decades a substantial and impressive development of a wide variety of thin film solar cells has been achieved. These include photovoltaic devices based on a large and versatile class of material systems such as organic semiconductors, inorganic semiconductors and more lately hybrid material blends or hybrid semiconductors. Furthermore, specific secondary materials properties, which provide extended functionality such as solution processing, have been the motivation driving these technologies. Additionally, compared to more conventional photovoltaics such as silicon solar cells, the device operation principles of many of these thin film photovoltaic technologies are dependent on complex physical mechanisms, such as excitonic processes, photo-induced charge separation, functional material interfaces.

Whereas initial research efforts were focused on understanding the underlying device physics and improvements in power conversion efficiency, with increasing maturity of these photovoltaic technologies, growing efforts are now being invested into the understanding of underlying degradation mechanisms and the improvement of device stability. In addition to efficiency, increased device lifetimes are fundamental requirements for transforming these technologies into an economic viability. In early studies, many stability investigations with various stress conditions were conducted in order to gain a better understanding of the degradation mechanisms. Currently, however, a consolidation towards some common stress 
scenarios for stability has been pursued in order to enable a better comparability between results of different research labs worldwide. A particularly well organized large scale effort was conducted within the framework of the International Summit on Organic Solar Cell Stability (ISOS), leading to the so-called ISOS-protocols. Nowadays these constitute a wellaccepted and generally followed standard within the organic photovoltaics (OPV) community. However, for commercialization of thin film photovoltaics, quite different stability tests need to be applied, as defined by the International Electrotechnical Commision (IEC, Genf, Switzerland) within the IEC 61646 documents. These IEC standards are applied to approve thin film solar modules with respect to security, quality and stability as a prerequisite for entering the international market. ${ }^{[1]}$

Within this report we aim to compare the existing testing standards for testing and certifying the stability of thin film photovoltaic technologies. We do this by pointing out commonalities and differences among them and by assessing their applicability and significance for various potential application scenarios. This will be accompanied with recommendations concerning the reporting of additional relevant stress parameters which are currently not considered in testing standards but that will further help identify key degradation mechanisms. Furthermore some general considerations about typical phenomena such as burn-in and long term degradation, their current understanding and their unambiguous determination along with additional suggestions concerning practical figures of merit will be discussed. Ultimately, the practical value of various stress tests will be analyzed concerning comparability, transfer from test to application, validity of acceleration factors and other parameters involved in the design of reliable, stable thin-film photovoltaics.

\section{Presentation of common approaches for studying solar cell stability}

\subsection{IEC 61646}

Long term performance, together with costs and efficiency, are the main parameters which determine the commercial success of a photovoltaic (PV) technology. The guaranteed 
reliability required for many applications, from grid-connected PV systems to buildingintegrated photovoltaics (BIPV), is around 20 years of practical lifetime or longer. Obviously, especially for new technologies entering the market, relying only on monitoring the performance of demonstrator field systems installed outdoors over timescales of decades is impractical. Therefore accelerated stress tests were developed to gauge the long term performance of PV devices in a much shorter time interval (i.e. typically months rather than years or decades).

On this matter, three widely adopted standards for photovoltaics have been proposed by the International Electrotechnical Committee (IEC) which are:

- IEC 61215: Crystalline silicon terrestrial photovoltaic (PV) modules -design qualification and type approval

- IEC 61646 : 'Thin-film terrestrial photovoltaic (PV) modules -design qualification and type approval',

- IEC 62108: Concentrator photovoltaic (CPV) modules and assemblies -design qualification and type approval.

Although they are often applied to the PV technologies which are not crystalline silicon or $\mathrm{CPV}$, the IEC 61646 qualification was designed mainly with amorphous silicon (a-Si) modules in mind and this must be considered when applying it directly to other technologies which have peculiar behavior under varying conditions like light, temperature etc. ${ }^{[2]}$ For next generation organic (OPV), perovskite (PSC) and even dye sensitized photovoltaics (DSSC), which lack specific industrial qualification tests, IEC 61646 currently represents the most applied standard for those industrials laboratories that aim to qualify the stability of next generation demonstrators in both the OPV and DSSC fields. ${ }^{[3]}$

The IEC 61646 sets up a sequence of tests, conditions and requirements for the qualification of a PV module. These are designed to represent the capability of the PV module to maintain 
performance under prolonged exposure to standard climates (defined in IEC 60721-2-1). ${ }^{\text {[2] }}$

The IEC 61646 tests and their sequences are shown in Figure 1.

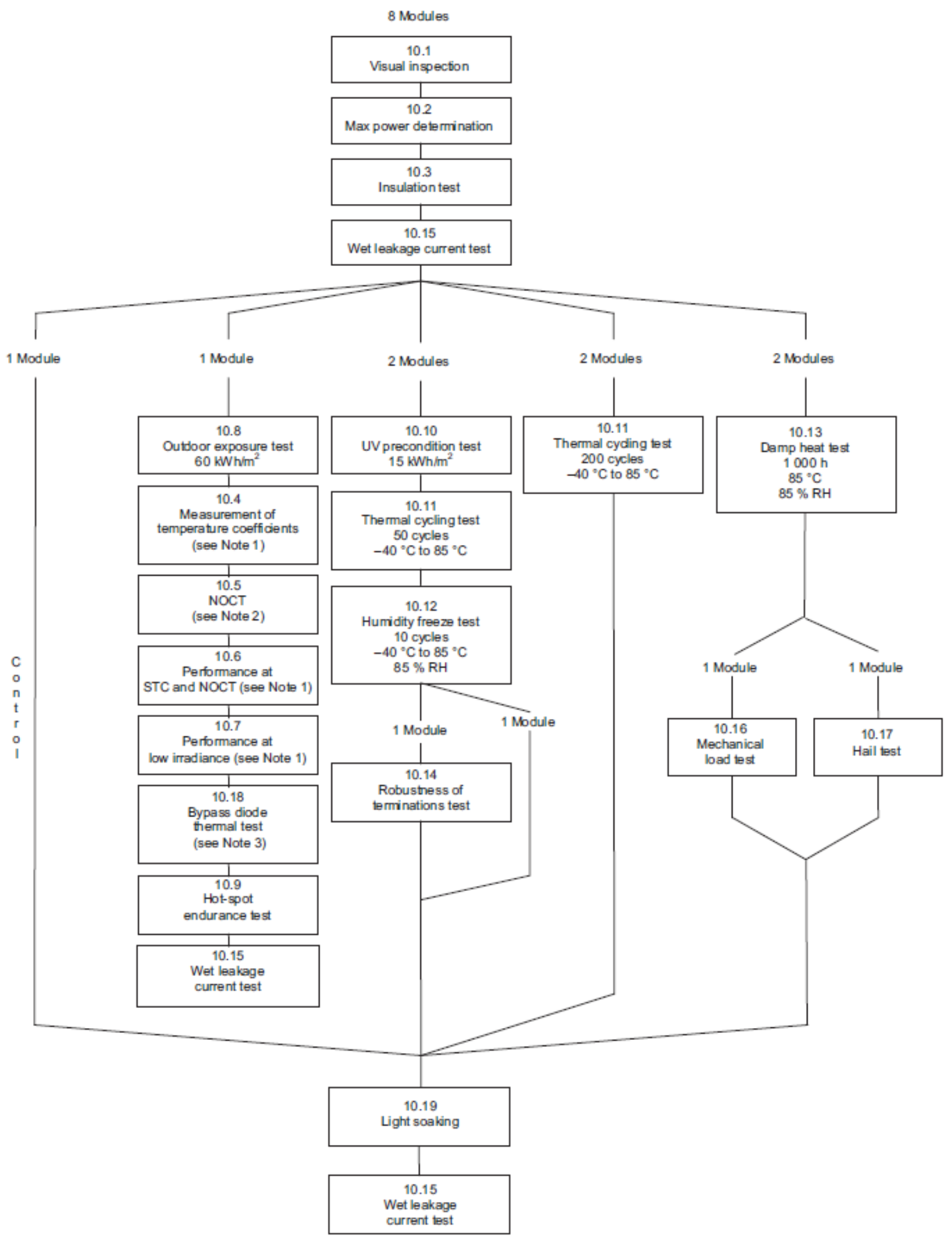

Figure 1: IEC 61646 qualification sequence for PV modules. ${ }^{[1]}$ 
The IEC 61646 qualification sequence is run on eight modules taken at random from a production batch or batches from a supplier who chooses to undergo the qualification. The first test carried out on all modules is a diagnostic visual inspection to detect "any visual defects". The modules are then tested for performance to determine the maximum power output in measurement conditions close to (but not as stringent) as standard test conditions. The subsequent insulation and wet leakage tests determine if there is sufficient electrical insulation between the current-carrying parts and the exterior both in dry and under wet operating conditions (moisture ingress). The latter test also verifies that moisture (e.g. caused by rain, dew, snow) does not enter the module, since it can cause corrosion or a safety hazard. A combination of these initial tests (especially the first and the third) are often repeated after each of the subsequent tests shown in the flow of Figure 1 and are specified in the text of the IEC 61646 document. For diagnostic purposes intermediate measurements of maximum power (10.2) may be undertaken before and after every individual test. The eight modules are then separated in 5 groups according to Figure 1.

One module undergoes a series of tests to determine performance and diagnostic parameters such as the Outdoor Exposure test which represents a short preliminary assessment of the module's ability to withstand exposure to outdoor conditions. The temperature coefficients, and the Nominal Operating Cell Temperature (NOCT) are performance tests. The Hot-Spot Endurance is a diagnostic test to gauge the ability of the module to withstand localized overheating caused by mismatched or faulty cells which can be forced into reverse bias. ${ }^{[2]}$ Similarly, the Bypass Diode Test, which constitutes an important safeguard against the effects of cell mismatch, gauges the endurance of the bypass diodes.

Two modules undergo UV preconditioning to determine degradation due to high energy UV photon exposure before undergoing a Thermal Cycling Test between the limits of $-40^{\circ} \mathrm{C}$ and $+85^{\circ} \mathrm{C}$ (50 cycles). Next these two modules undergo a Humidity Freeze Test. This is an environmental test corresponding to 10 complete cycles with a high limit of $85^{\circ} \mathrm{C}$ (with high 
relative humidity requirement of $85 \%$ ) and low limit at $-40^{\circ} \mathrm{C}$. One module is then subjected to a mechanical test which verifies the Robustness of Terminations.

Two other modules undergo a longer Thermal Cycling of 200 cycles $\left(-40^{\circ} \mathrm{C} /+85^{\circ} \mathrm{C}\right)$ to test the ability of the modules "to withstand thermal mismatch, fatigue and other stresses caused by repeated changes of temperature" ${ }^{[1]}$ while another pair are subjected to a Damp Heat Test of $1000 \mathrm{~h}$ at $+85^{\circ} \mathrm{C}$ and a relative humidity of $85 \%$ to gauge the durability of the devices to high temperatures and humidity permeation. After the Damp Heat Test, one module is subjected to a Mechanical Load test and the other a Hail Test which determine the resistance to mechanical loads/impacts after a prolonged environmental test.

According to the flow in Figure 1, six modules, together with a control device, are subjected to a Light Soaking Test and a final Wet Leakage Current test.

To stabilize the electrical characteristics of thin-film modules by means of natural sunlight or simulated solar irradiation, the Light Soaking Test is the final major test which wraps up the IEC 61646 qualification. The modules, under a resistive load, are subjected to irradiation until their maximum power output, $P_{\max }$, stabilizes at irradiances between $600-1000 \mathrm{~W} / \mathrm{m}^{2}$ and temperatures ranges between $40^{\circ} \mathrm{C}$ and $60^{\circ} \mathrm{C}$. $\mathrm{P}_{\max }$ must be stable within $2 \%$ after two consecutive exposures of at least $43 \mathrm{kWh} \cdot \mathrm{m}^{-2}$. The value of the stabilized $\mathrm{P}_{\max }$ is then again checked against the minimum value as marked by the manufacturer. In order to pass this final test, the maximum output power at STC must not be less than $90 \%$ of the minimum value specified by the manufacturer.

\section{$2.2 \quad$ ISOS-protocols}

With the rapid increase in OPV performance during the last decade, there has been an increasing awareness in the research community for the growing need to establish generalized stability testing conditions, enabling improved comparability between lifetime values reported from different research labs. Based on reports and discussions from the first three International Summits on OPV Stability (ISOS) in 2008, 2009 and 2010, the so-called "ISOS- 
protocols" were defined. These were summarized in a publication entitled "Consensus stability testing protocols for organic photovoltaic (OPV) materials and devices" in $2011 .{ }^{[4]}$ In response to the lack of practical guidelines for intercomparable OPV stability tests, the aim of the ISOS community was to establish standard procedures for accurate lifetime estimations of organic thin film solar cell devices. The protocols were intended to provide more tailored criteria to investigate OPV stability than was outlined in the existing IEC $61646^{[1]}$, which is intended for the commercial qualification of terrestrial thin film photovoltaic modules but not for elucidating degradation pathways and identifying key mechanisms limiting device lifetimes. One major motivation for developing the ISOS protocols was to identify parameters which influenced device stability in order to enable reasonable accuracy in the comparison between reported stability and lifetime data for organic thin film devices. The ISOS study aims to coordinate efforts to gather as much information about OPV degradation and stability in a controlled manner such that qualification tests, which may be more suitable or detailed than the IEC 61646, can be developed.

The ISOS protocols were initially developed to classify the guidelines into different fundamental stress conditions to imitate the requirements of specific applications. Furthermore, three levels of execution are defined for each fundamental stress condition with increasing complexity and demand on measurement equipment and accuracy. These various complexity levels were introduced to enable the possibility for virtually every researcher to follow these guidelines. This introduced flexibility for stability studies in the field. On the one hand, laboratories with limited budget and infrastructure can still produce results which are comparable with other studies. On the other hand, the advanced procedures match standardized tests in certified labs which provide a benchmark for characterizing photovoltaic technologies. In Table 1, a summary of the aforementioned fundamental stress conditions and different levels of execution is shown. The five different testing conditions are "Dark", "Outdoor", "Laboratory weathering testing", "Thermal cycling" and "Solar-thermal-humidity 
Cycling". "Dark"-storage at different temperatures elucidates the influence of ambient air and thermal stress. Ingress of water and oxygen through the sealing and morphological changes within the bulk heterojunction are the main degradation issues under these conditions. Statements about the shelf life of a device can be extrapolated from these test results. "Laboratory weathering testing" applies light and continuous electrical stress - by load and by periodic in-situ current-voltage (IV)-characterization - as additional stress conditions. Thus, additional energy - by irradiation and electrical current - is introduced and further degradation mechanisms, such as photo-oxidation and electro migration, can be detected. Interestingly, a very fast initial decay of power conversion efficiency - the so-called burn-in is commonly observed while applying this testing protocol. Since burn-in is often not observed under dark conditions, its origin is very likely to be related to light and/or electrical stress. Please refer to section 5 for more information. The testing conditions "Thermal cycling" and "Solar-thermal-humidity cycling" are inspired by IEC's 61646 "10.11 Thermal cycling test" and "10.12 Humidity freeze test" although the application of illumination is beyond the IEC 61646 protocols. These testing procedures are meant to elucidate the devices' ability to withstand thermal mismatch, fatigue and other stresses caused by repeated changes of temperature and - in case of additional incident light - large temperature gradients. Since these stress conditions are very close to official qualification for industrial products, these are usually not applied within scientific studies. Last but not least, an "Outdoor" testing condition is described. Although this testing condition is indisputably very close to the real application of terrestrial PV, it is not very well defined, since the measurement conditions significantly change between locations and seasons. ${ }^{[5]}$ Notably, the spectrum of the sunlight rarely matches the standardized AM1.5 or AM1.5G spectra, ${ }^{[6]}$ as these are based on theoretical assumptions in the 1970s, which have, in the meantime, been found to deviate considerably from real conditions. 
Table 1: Summary of measurement guidelines for the different stress conditions and levels of execution nrovided within the ISOS nrotomols hv Repse at al. [4]

\begin{tabular}{|c|c|c|c|c|c|c|c|c|}
\hline \multicolumn{9}{|l|}{ Three levels } \\
\hline \multirow{3}{*}{\multicolumn{2}{|c|}{$\begin{array}{l}\text { Basic (Level 1) } \\
\text { Intermediate (Level 2) } \\
\text { Advanced (Level 3) }\end{array}$}} & \multirow{2}{*}{\multicolumn{7}{|c|}{ "Hand held" measurements using the simplest equipment and few conditions }} \\
\hline & & & & & & & & \\
\hline & & & & Stanc & dardized tests ap & applied in certified labs. & Extended range of par & arameters to monitor, etc. \\
\hline \multicolumn{2}{|l|}{ Test type } & \multicolumn{4}{|l|}{ Dark } & \multicolumn{3}{|l|}{ Outdoor } \\
\hline \multicolumn{2}{|l|}{ Test ID } & ISOS-D-1 Shelf & \multicolumn{2}{|c|}{$\begin{array}{l}\text { ISOS-D-2 High temp. } \\
\text { storage }\end{array}$} & $\begin{array}{l}\text { ISOS-D-3 Damp } \\
\text { heat }\end{array}$ & $\begin{array}{l}\text { ISOS-O-1 } \\
\text { Outdoor }\end{array}$ & $\begin{array}{l}\text { ISOS-O-2 } \\
\text { Outdoor }\end{array}$ & ISOS-O-3 Outdoor \\
\hline \multicolumn{2}{|l|}{ Light source } & None & \multicolumn{2}{|c|}{ None } & \multicolumn{2}{|c|}{ None $\quad$ Sunlight } & Sunlight & Sunlight \\
\hline \multicolumn{2}{|c|}{ Temp. $^{\mathrm{a}}$} & \multirow{2}{*}{$\begin{array}{l}\text { Ambient } \\
\text { Ambient }\end{array}$} & \multicolumn{2}{|l|}{$65 / 85^{\circ} \mathrm{C}$} & $65 / 85^{\circ} \mathrm{C}$ & Ambient & Ambient & Ambient \\
\hline \multirow{2}{*}{\multicolumn{2}{|c|}{$\begin{array}{l}\text { Relative humidity (R.H.) } \\
\text { Environment }^{\mathrm{a}}\end{array}$}} & & \multicolumn{2}{|l|}{ Ambient (low) } & $85 \%$ & Ambient & Ambient & Ambient \\
\hline & & Ambient & \multicolumn{2}{|l|}{ Oven } & Env. chamber & Outdoor & Outdoor & Outdoor \\
\hline \multicolumn{2}{|c|}{$\begin{array}{l}\text { Characterization light } \\
\text { source }\end{array}$} & $\begin{array}{l}\text { Solar simulator or } \\
\text { sunlight }\end{array}$ & \multicolumn{2}{|l|}{ Solar simulator } & Solar simulator & Solar simulator & Sunlight & $\begin{array}{l}\text { Sunlight and solar } \\
\text { simulator }\end{array}$ \\
\hline \multicolumn{2}{|c|}{ Load $^{\mathrm{b}}$} & Open circuit & Open circuit & & Open circuit & $\begin{array}{l}\text { MPP or open } \\
\text { circuit }\end{array}$ & $\begin{array}{l}\text { MPP or open } \\
\text { circuit }\end{array}$ & MPP \\
\hline Test type & Labot & ratory weathering & g testing & & & Thermal cycling & & \\
\hline Test ID & $\begin{array}{l}\text { ISOS- } \\
\text { weatl }\end{array}$ & $\begin{array}{l}\text {-L-1 Laboratory } \\
\text { hering }\end{array}$ & $\begin{array}{l}\text { ISOS-L-2 Laboratory } \\
\text { weathering }\end{array}$ & $\begin{array}{l}\text { ISOS-L-3 } \\
\text { weatheri }\end{array}$ & $\begin{array}{l}\text { Laboratory } \\
\text { ing }\end{array}$ & $\begin{array}{l}\text { ISOS-T-1 Thermal } \\
\text { cycling }\end{array}$ & $\begin{array}{l}\text { ISOS-T-2 Thermal } \\
\text { cycling }\end{array}$ & $\begin{array}{l}\text { ISOS- T-3 Thermal } \\
\text { cycling }\end{array}$ \\
\hline Light source & Simul & lator & Simulator & Simulato & & None & None & None \\
\hline Temp. ${ }^{\mathrm{a}}$ & Ambi & ient & $65 / 85^{\circ} \mathrm{C}$ & $65 / 85^{\circ} \mathrm{C}$ & & $\begin{array}{l}\text { Between room temp. } \\
\text { and } 65 / 85^{\circ} \mathrm{C}\end{array}$ & $\begin{array}{l}\text { Between room temp. } \\
\text { and } 65 / 85^{\circ} \mathrm{C}\end{array}$ & -40 to $+85^{\circ} \mathrm{C}$ \\
\hline $\begin{array}{l}\text { Relative humidity } \\
\text { (R.H.) })^{\mathrm{a}}\end{array}$ & Ambi & & Ambient & Near 50 & & Ambient & Ambient & Near $55 \%$ \\
\hline Environment/setup & Light & only & Light \& Temp. & Light, $\mathrm{Te}$ & emp. and R.H. & Hot plate/oven & Oven/env. chamb. & Env. chamb. \\
\hline $\begin{array}{l}\text { Characterization } \\
\text { light source }\end{array}$ & Solar & simulator & Solar simulator & Solar sin & nulator & $\begin{array}{l}\text { Solar simulator or } \\
\text { sunlight }\end{array}$ & Solar simulator & Solar simulator \\
\hline Load $^{\mathrm{b}}$ & MPP & or open circuit & MPP or open circuit & MPP & & Open circuit & Open circuit & Open circuit \\
\hline Test type & & Solar-thermal-h & umidity Cycling & & & & & \\
\hline Test ID & & ISOS-LT-1 solar-t & hermal cycling & & $\begin{array}{l}\text { ISOS-LT-2 solar } \\
\text { cycling }\end{array}$ & r-thermal-humidity & $\begin{array}{l}\text { ISOS-LT-3 solar-ther } \\
\text { cycling }\end{array}$ & ermal-humidity-freeze \\
\hline Light source & & Simulator & & & Simulator & & Simulator & \\
\hline Temp. & & $\begin{array}{l}\text { Linear or step ra } \\
65^{\circ} \mathrm{C}\end{array}$ & mping between room $\mathrm{t}$ & emp. and & Linear ramping & ig between 5 and $65^{\circ} \mathrm{C}$ & Linear ramping betv & tween -25 and $65^{\circ} \mathrm{C}$ \\
\hline Relative humidity ( & 2.H.) & Monitored, uncor & ntrolled & & $\begin{array}{l}\text { Monitored, con } \\
40^{\circ} \mathrm{C}\end{array}$ & ntrolled at $50 \%$ beyond & Monitored, controlle & lled at $50 \%$ beyond $40{ }^{\circ} \mathrm{C}$ \\
\hline Environment/setup & & Weathering chan & nber & & Env. chamb. wi & vith sun simulation & $\begin{array}{l}\text { Env. chamb. with st } \\
\text { freezing }\end{array}$ & sun simulation and \\
\hline $\begin{array}{l}\text { Characterization lig } \\
\text { source }\end{array}$ & & Solar simulator & & & Solar simulator & & Solar simulator & \\
\hline Load $^{\mathrm{b}}$ & & MPP or open circ & cuit & & MPP or open ci & circuit & MPP or open circuit & \\
\hline
\end{tabular}

a The ambient conditions are defined as $23^{\circ} \mathrm{C} / 50 \% \mathrm{RH}$ in general, and $27^{\circ} \mathrm{C} / 65 \% \mathrm{RH}$ accepted in tropical countries according to ISO 291(2008): Plastics-Standard atmospheres for conditioning and testing.

$\mathrm{b}$ Open circuit refers to a simply disconnected device or device connected to a sourcemeter set to 0 current.

For all testing conditions within the ISOS-protocols, a large number of actual measurement conditions are defined - often even the exact figures for parameters like the temperature with increasing accuracy for each level of execution. Nevertheless, the most common testing procedure used by the community since 2011 - the laboratory weathering testing ISOS-L has resulted in many discussions regarding the light source used for artificial illumination.

Several commonly used light sources were discussed by Reese et al. regarding their applicability for ISOS-L tests, Table 2). Only two lamp types, Xenon arc and metal halide, were able to match the standardized AM1.5G spectrum closely enough and are thus best suited for ISOS-L testing. Nowadays, there are some LED-light sources which are also able to simulate the whole sunlight spectrum very well, albeit these light sources can be extremely expensive. In order to avoid large investments as a requirement for stability testing, all lamp 
types are accepted for reporting ISOS-L1 conform results, although a critical discussion and comparison of the results as well as reporting the specific light source employed are mandatory.

Table 2: Overview of artificial light sources and rating in accordance with ISOS-L protocols ${ }^{[4]}$.

\begin{tabular}{|c|c|c|}
\hline Type of light source & Comments & Comparison to AM 1.5G \\
\hline Sulfur plasma & $\begin{array}{l}\text { Broad continuous spectrum in the visible and IR range, cannot reach class A } \\
\text { designation for spectral match between } 400 \text { and } 1100 \mathrm{~nm} \\
\text { No significant emission in the UV range }\end{array}$ & Does not match AM $1.5 \mathrm{G}$ \\
\hline Tungsten halogen & $\begin{array}{l}\text { Broad continuous spectrum in the visible and IR range, cannot reach class A } \\
\text { designation for spectral match between } 400 \text { and } 1100 \mathrm{~nm} \\
\text { No significant emission in the UV range } \\
\text { Spatial uniformity issues to be expected }\end{array}$ & Does not match AM 1.5G \\
\hline LED lamps & $\begin{array}{l}\text { Tunable colors. Large array of LEDs can simulate light approaching AM1.5G (see for } \\
\text { example, [23]), but single LEDs cannot presently reach Class A designation from } 400 \text { to } \\
1100 \mathrm{~nm}\end{array}$ & Does not match AM 1.5G \\
\hline $\begin{array}{l}\text { UVA and UVB fluorescent } \\
\text { tubes }\end{array}$ & $\begin{array}{l}\text { UVA lamps: good match to daylight between } 290 \text { and } 340 \mathrm{~nm} \text {, no emission in the } \\
\text { visible and IR ranges } \\
\text { UVB lamps: important emission below } 290 \mathrm{~nm} \text {, no emission in the visible and IR } \\
\text { ranges }\end{array}$ & Do not match AM 1.5G \\
\hline $\begin{array}{l}\text { Medium pressure } \\
\text { mercury arc }\end{array}$ & $\begin{array}{l}\text { Discrete emission of nearly monochromatic radiation between } 290 \text { and } 560 \mathrm{~nm} \text {. No } \\
\text { radiation emitted beyond } 560 \mathrm{~nm}\end{array}$ & Does not match AM 1.5G \\
\hline Xenon arc & $\begin{array}{l}\text { Very good match to AM1.5G with appropriate filtering, can meet class A requirements } \\
\text { for spectral match } \\
\text { Lamp aging tends to affect more UV range over other ranges, so monitoring in UV } \\
\text { range is critical to maintain proper irradiance level }\end{array}$ & $\begin{array}{l}\text { Good match AM1.5G (with correct } \\
\text { filter system) }\end{array}$ \\
\hline Metal halide & $\begin{array}{l}\text { Very good match to AM1.5G with appropriate filtering, can meet class A requirements } \\
\text { for spectral match (metal halide global types), require stable source of electrical power } \\
\text { for stability of emission spectrum }\end{array}$ & Good match AM1.5G (certain types) \\
\hline
\end{tabular}

Beside suggestions and guidelines for measurement procedures, the ISOS protocols describe the correct presentation for stability data and reporting of operational lifetimes. For the most common ISOS protocol, the laboratory weathering testing, ISOS-L, a periodic in-situ IVmeasurement is performed. With that, a temporal evolution of the IV-parameters, especially the power conversion efficiency, can be plotted. A schematic example for a typical temporal development of the solar cell performance is given in Figure 2. Usually a fast initial decay of the PCE - the burn-in - is followed by a slow long term decay that defines the operational lifetime of the device. Typically four points on the efficiency versus time curve are identified. These can be used to define the operational lifetime with and without stabilization of an OPV device tested under ISOS-L conditions. In Table 3, these parameters are listed and defined. A critical point is that $\mathrm{T}_{\mathrm{S}}$ - the end of burn-in is "defined arbitrarily by the user". In section 5, a more objective definition of this parameter is introduced. 


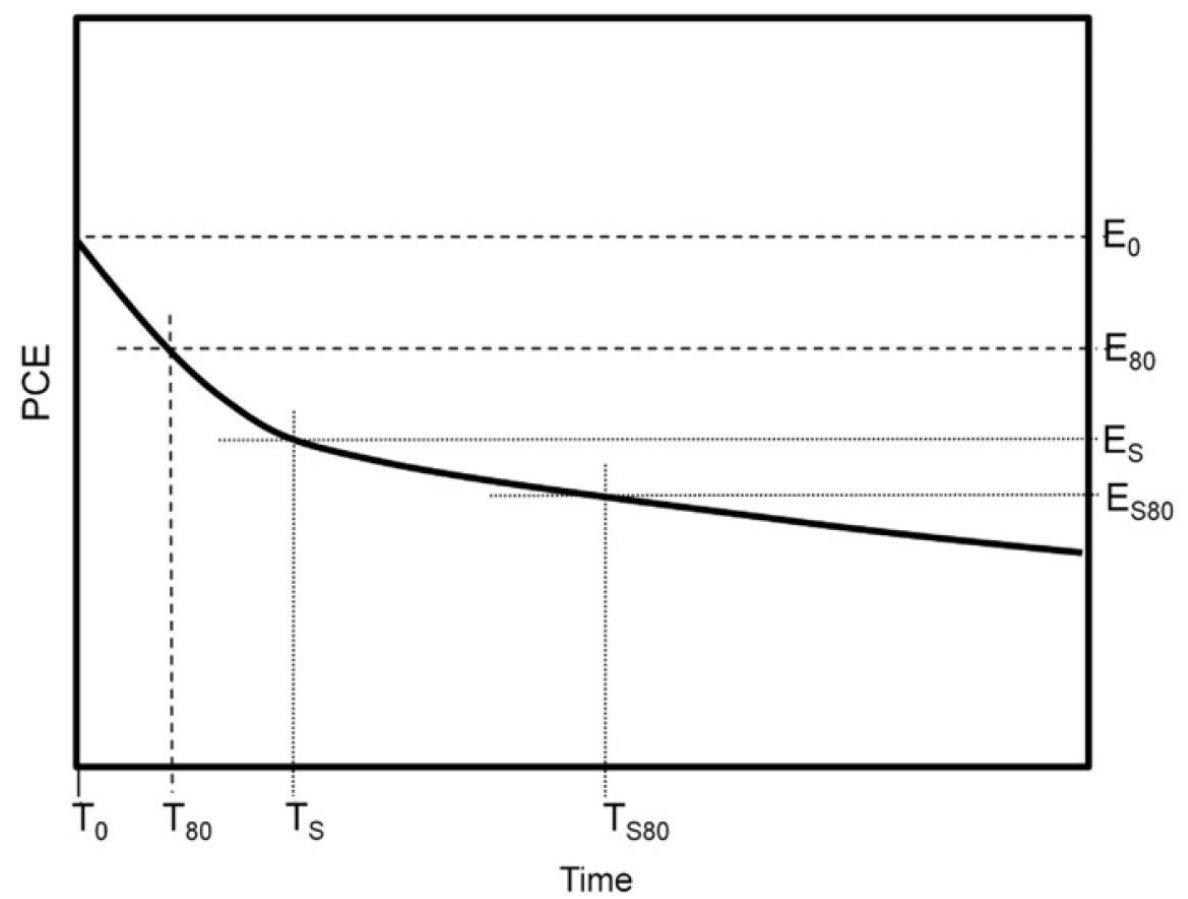

Figure 2: Schematic temporal evolution of the power conversion efficiency derived by ISOS-L protocol. ${ }^{[4]}$ Four typical points of the curve are used to define OPV device stability as explained in Table 3.

Table 3: Definition of the four points needed to define OPV device stability according to Reese et al. ${ }^{[4]}$

$\begin{array}{cl}E_{0}, T_{0} \quad \begin{array}{l}E_{0} \text { is the initial testing measurement of an OPV device immediately } \\ \text { after final fabrication of the device, at time }=0, T_{0} .\end{array} \\ E_{\mathrm{S}}, T_{\mathrm{S}} \\ \begin{array}{l}E_{\mathrm{S}} \text { is a second testing measurement of an OPV device, defined } \\ \text { arbitrarily by the user as some time, } T_{\mathrm{S}} \text {, after the fabrication of a } \\ \text { device. }\end{array} \\ E_{80}, T_{80} \quad \begin{array}{l}E_{80} \text { is the testing measurement of an OPV device after the device has } \\ \text { decayed } 20 \% \text { from the initial testing measurement, } E_{0} . T_{80} \text { is the time } \\ \text { it took to decay to } E_{80} .\end{array} \\ E_{\mathrm{S} 80}, & \begin{array}{l}E_{\mathrm{S} 80} \text { is the testing measurement of an OPV device after the device has } \\ \text { decayed } 20 \% \text { from the second testing measurement, } E_{\mathrm{S}} . T_{\mathrm{S} 80} \text { is the } \\ \text { time it took to decay to } E_{\mathrm{S} 80} .\end{array}\end{array}$

In summary, the proposed ISOS-protocols represent a large spectrum of defined stress

conditions and thus enable researchers to collect and report data related to solar cell stability in a reproducible and comparable manner. And even though these tests were created with OPV in mind, the stress conditions are universal and the protocols can also be applied for other thin-film photovoltaic devices such as DSSCs and perovskite solar cells.

\subsection{Comparison of the IEC and ISOS protocols}

In general, the IEC 61646 international standard is intended to be an official test procedure to approve commercial terrestrial thin film solar modules before sale, with focus on the electrical and thermal characteristics, capability of withstanding exposures of climate and other stress 
tests for safety qualification. This qualification is typically carried out by officially certified testing labs. The ISOS-protocols instead aim to provide guidelines of reduced, medium or advanced complexity to enable researchers to report comparable OPV stability values under specific stress conditions.

While there is in part substantial similarity between the documents, e.g. both present procedures for testing device stability with very detailed measurement conditions for each stress condition, they also differ significantly in many aspects. Particularly noticeable is that IEC 61646 specifies distinct durations for each stability test, while ISOS-protocols do not. IEC 61646 offers a range of acceptable parameters, but does not allow any deviation from the given procedures, while ISOS-protocols allow different levels of complexity and accuracy. Furthermore, IEC 61646 largely provides test procedures that simulate extreme external stress conditions, like mechanical load, hail or high external voltage. Further tests include bypass diode, hot spot endurance, and specific safety tests (insulation and wet leakage). All these tests intend to confirm device safety and qualify the device for sale.

Differences between the ISOS and IEC protocols are due to the different specific aims of both documents. IEC 61646 aims to identify potential key failures of commercial devices, whereas the ISOS recommendations are meant to delve in a systematic study of degradation mechanisms and provide accurate long term prediction on device stability, ultimately providing a flexible framework in which short and long term degradation mechanisms of thin film OPV devices can be reliably detected and analyzed. Therefore, ISOS-protocols are useful in the development phase of new photovoltaic devices in order to improve overall long term stability and lifetime, as well as identify approaches for constructive device stabilization. Nevertheless, the initial idea to compile the ISOS-protocols has its seeds in the IEC 61646 tests. In fact, the "light-soaking" - or "laboratory weathering testing", "outdoor" and "thermal cycling" tests are very similar in both documents, but with higher flexibility in ISOSprotocols. 


\section{Useful extensions for ISOS-lifetime studies}

The ISOS-protocols ${ }^{[4]}$ represent the backbone and state-of-the-art of current efforts in studying OPV device stability. Nevertheless, in the meantime a learning process has taken place within the scientific community, yielding the possibility for improved precision in reporting testing conditions. Specifically, several ambiguities related to the reporting of testing parameters have been recognized. In this section, reporting of more precise testing parameters and methods for data documentation are proposed.

One specifically important stress parameter during aging is the temperature of the device. However, due to the flat geometry and sealing of the solar cells, it is difficult to measure cell temperature directly. The ISOS-protocols suggest measuring temperature behind the solar cell in case of laboratory weathering - without further specification. This is indeed the best location to measure the temperature as closest as possible to the device stack. However, there are additional temperature measurements that should be considered, particularly as it is not always trivial to control the temperature within a setup for each sample individually. Often the solar cells are packaged with glass or plastic foil - both of which exhibit rather low thermal conductivities. Therefore, measurements behind the cell - or even in direct contact with the device may not give an accurate temperature for the solar cell itself. Hence we suggest taking additional measurement points within the measurement chamber, for example within the shadow, within the light and at the side of the sample holder to have a number to comparable values. In Error! Reference source not found., an example of the sensitivity of device performance on ambient temperature is demonstrated. In this particular example the room temperature, controlled by air conditioning, was changed by $5^{\circ} \mathrm{C}$ at ca. $1400 \mathrm{~h}$ stressing time. The impact on open circuit voltage is clearly visible, although the sample temperature changed by much less than $5^{\circ} \mathrm{C}$ within the measurement chamber. 


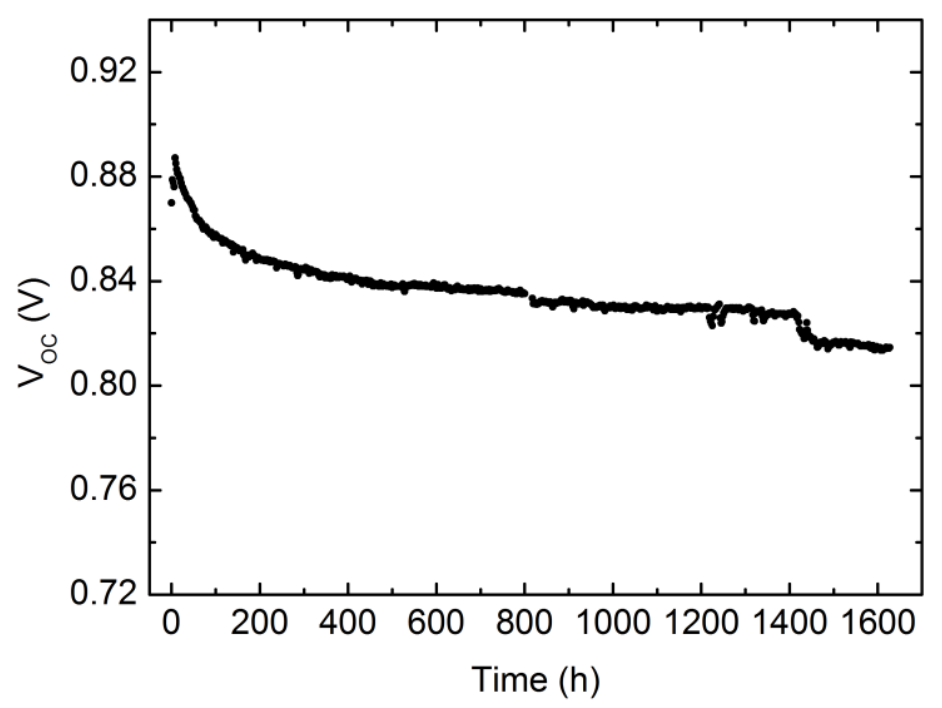

Figure 3: Influence of ambient temperature change of only $5^{\circ} \mathrm{C}$ on device performance during ISOS-L1 experiment at $1400 \mathrm{~h}$. Without proper reporting one might interpret the kink as a drastic failure, which it is not.

In case of temperature control as demanded for the laboratory weathering for ISOS-L2 and ISOS-L3, the practical error margins within which the temperature may vary should be documented as well. In general there should be as much information gathered as the complexity of the experiment demands. In other words, in addition to the approximated sample temperature, accuracy can be improved by reporting temperature values at additional locations within the setup, both in the light and in the shadow.

The same should also be done for the relative humidity $(\mathrm{RH})$, as this parameter is extremely dependent on the ambient temperature. For example, $50 \% \mathrm{RH}$ at $25^{\circ} \mathrm{C}$ in the room around the ISOS-L testing setup corresponds approximately to $5 \% \mathrm{RH}$ at $65^{\circ} \mathrm{C}$ within the ISOS-L testing chamber.

As already presented in section 1a, knowledge of the artificial light source spectrum is essential for reliable stability measurements. However, we propose that both the initial and final spectrum of the lamp should be reported, and not only the initial spectrum as originally stated in the ISOS-protocols. In the ideal case, a continuous spectrum is recorded to follow potential aging of the lamp itself. Whereas no temporal spectrum information is required for 
ISOS-L1, we suggest to apply this condition for ISOS-L2 \& L3 testing, so that spectral changes, especially in the UV, are accurately documented.

Whereas the original ISOS-protocols describe a "reasonable rule of thumb" for the voltage range used in current-voltage (IV) characterization, related to the open circuit voltage ( $\left.\mathrm{V}_{\mathrm{OC}}\right)$ of the device $\left(\left[-2^{*} \mathrm{~V}_{\mathrm{OC}},+3^{*} \mathrm{~V}_{\mathrm{OC}}\right]\right)$, the exact voltage range applied is often not reported. However, we have recently discovered a large influence of the applied voltage range on the degradation behavior of organic solar cells, as shown in Figure 4. ${ }^{[7]}$

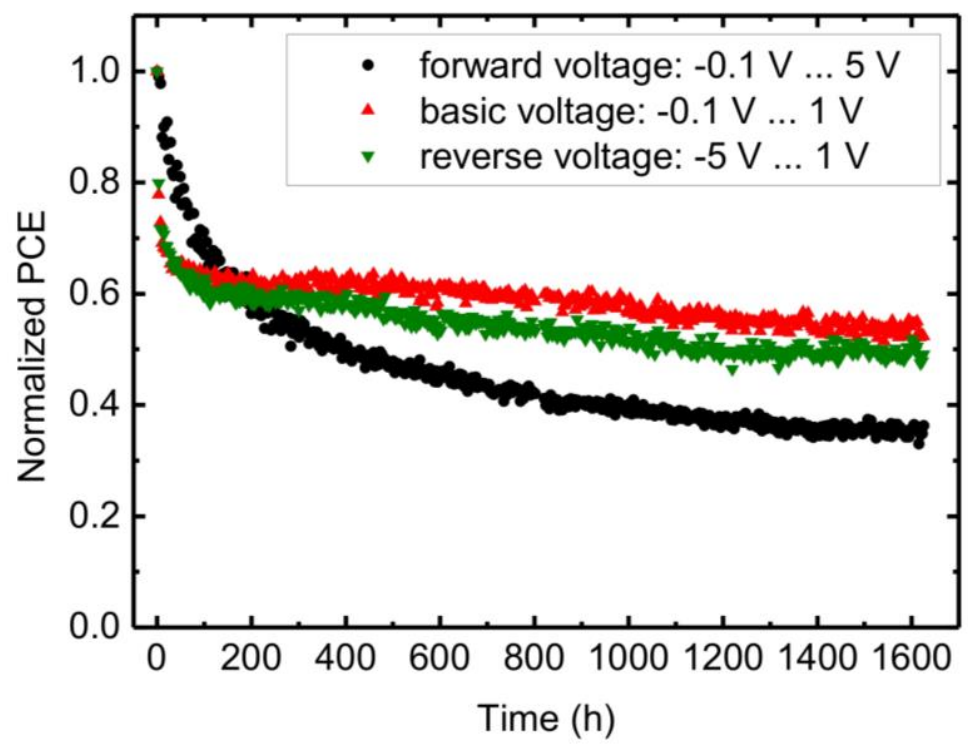

Figure 4: Influence of the current-voltage characterization range on the degradation behavior of PCDTBT:PC 70 BM organic solar cells, aged under ISOS-L1 conditions. Reprinted with permission. ${ }^{[7]}$

Specifically large forward voltages (i.e. large currents leading to electrical stress) increased the degradation rates considerably and even modified the form and the burn-in behavior. Hence care should be taken when making conclusions on the burn-in or lifetime of devices, since under normal operational conditions no forward voltages are applied. Thus, besides other ambiguities, periodic IV-characterization, e.g. conducted every thirty minutes, during an ISOS-L-experiment may result in an underestimation of operational lifetimes. In conclusion, we consider it mandatory to report the voltage range used in IV-characterization for better comparability among experiments performed in different laboratories. 
Additionally, the maximum currents reached during IV sweep, the sweep rate, the duration of a single measurement and the number of periodic measurements should be reported, as these can further impact results from stability testing.

Finally there is no standard for reporting lifetime decay curves. Sometimes the temporal development is documented by no more than 10 total data points for long term experiments lasting 1000 hours or more. These may also include considerable scatter, making a statistical assessment rather difficult. In order to yield statistically relevant information we therefore recommend at least 100 measurement points combined with statistical information obtained by averaging over a specified number of identical devices. The resulting decay curves then enable the extraction of general trends for the degradation kinetics, thus allowing more generalized conclusions. Furthermore, the presentation of all photovoltaic parameters instead of only one - usually the PCE - increases understanding of the degradation behavior and physical reasons thereof. Therefore we suggest to always present lifetime decay curves for all photovoltaic parameters.

\section{Bridging the gap between scientific and industrial evaluations}

\subsection{Focus of scientific studies}

Progress on the understanding of the different degradation mechanisms occurring in OPVs was initiated back in the $1990 \mathrm{~s} .{ }^{[8]}$ Since then, the stability of OPVs has been greatly improved, reaching outdoor lifetimes of several years.

In fact, together with the above, there are several high priority areas for short to medium term research and development in organic photovoltaics. These include:

i) the development of large area, monolithic submodule architectures to reduce cost and manufacturing complexity;

ii) the replacement of costly components such as the current transparent conducting electrode materials (indium tin oxide) with lower cost alternatives;

iii) the creation of new low - cost barrier materials to improve module lifetime; and 
iv) the development of "thick junction" cells to reduce defect density and improve manufacturing yield. These are the necessary elements for the organic photovoltaics “Technology Roadmap" to move forward. Here we focus on some of the aspects regarding lifetime.

Standards and protocols currently used for OPV stability analyses are defined based on previous experience with Silicon solar cells, focused mainly on outdoor long-term module applications. ${ }^{[4]}$ Nevertheless, as described above, next generation thin film photovoltaics such as OPVs, but also DSSC or Perovskite solar cells, have the potential for other types of application niches, and thus new and specific protocols for testing stability and lifetime are required. The lessons learned from inter-laboratory collaborations ${ }^{[9]}$ and round robin studies ${ }^{[5}$, ${ }^{9 b, 10]}$ have shown that since OPVs are in continuous development, a wide diversity of materials, device configuration and device fabrication methods are used. This makes comparison between similar OPV types highly difficult and general "rules-of-thumb" cannot be easily generated. Even simple tests performed in different laboratories for similar devices have often presented a large spread in results from ageing tests. ${ }^{[5,11]}$ Also, the analysis of OPV devices, degraded in a similar manner following the same ISOS protocols is not enough to easily unravel degradation mechanisms since the application of combined characterization techniques are usually required to understand degradation. ${ }^{[12]}$ Attention should also be directed towards the possible degradation pathways observed on devices fabricated at laboratory scale in comparison with devices fabricated at large scale (e.g. printed or vacuum roll to roll fabrication). ${ }^{[13]}$ Whereas laboratory cells are a way to analyse new concepts, new materials or new architectures, large area devices can differ in their fabrication depending on the requirements for flexible and low cost fabrication. For example, the use of solvents or additives in large-scale fabrication can be highly different from what is used in the laboratory as boiling point, substrate compatibility and annealing temperature will be limited to a few materials. ${ }^{[14]}$ The inverted configuration OPV is probably the most employed for large area 
printing methods due to the lack of stable metal pastes for the back electrode (e.g. Al). The same happens with barrier layers and ITO-free electrodes. Whereas the industrial protocols have a precise sequence of tests and descriptions of what defines a failure, they are typically not currently designed to understand the details of the mechanisms that lead to device degradation over time in particular depth. The continual progress of scientific studies in understanding these degradation mechanisms and the role of both the different photoactive materials and their combinations (photoactive, contacts, barriers, etc), and the environment (e.g. light, temperature, gas permeation) is thus extremely important in competing or bringing a PV technology to the market. Of the new technologies (OPV, DSSCs and perovskites), perhaps the OPV filed has been more active in not only carrying out studies but as we have also seen in designing ad-hoc protocols. There is also a need to find methods where the ISOS protocols and Standards can be applied regardless of the fabrication method of the device or its architecture.

Recently, Corazza et al. reported a promising method to predict, categorize and compare the lifetime of OPVs applying different ISOS protocols. OPV samples were fabricated applying the same active layer material (P3HT:PCBM), produced using two processing techniques (spin coating on flexible and glass substrates, and roll to roll slot dye coating on glass substrates) and sealed with three different levels of encapsulation. ${ }^{[1]}$ The motivation for selecting the variability in the preparation of samples was to reveal the possible range of aging rates for a single active layer material, and by doing so, establish relevant acceleration factors for lifetime testing. The method allowed categorizing the level of performance of P3HT:PCBM under different ISOS tests conditions regardless of the diversity of the device architectures, as shown in Figure 5. The method was able to establish that P3HT:PCBM devices with common encapsulation techniques show an average stable performance of up to years under moderate test conditions (corresponding to ISOS-D-1 and D-2 storage) and only up to weeks and months under harsh test conditions (ISOS-D-3, L-2 and L-3). It also allowed 
establishing acceleration factors for the different ISOS tests and the improvement factors in stability after encapsulation.

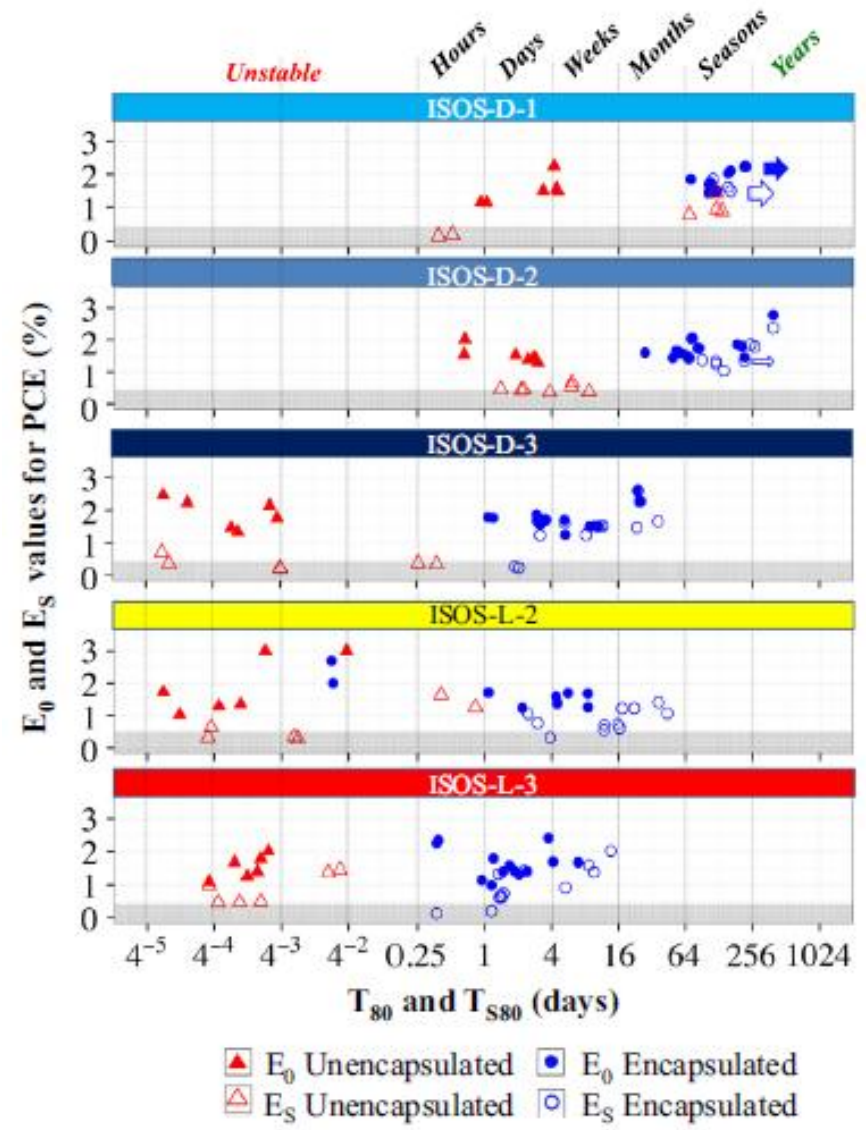

Figure 5: The o-diagram presenting the $T_{80}$ (solid markers) and $T_{s 80}$ (open markers) values for all the tested samples under different ISOS tests conditions. The blue circles and the red triangles represent the devices with and without encapsulation, respectively. The gray zone markers are the area in which the devices are considered fully degraded (below $30 \%$ of initial performance). The arrow shows the data that represents $\mathbf{T}_{\text {final }}$ instead of $\mathbf{T}_{80}$, which can be much higher. Copyright SOLMAT. ${ }^{[11]}$

The work reported by Corazza et al. presents a method that allows the analysis of the stability of OPVs independently of issues not related to the active material itself, like the fabrication technique or encapsulation. This report also provides a new insight into how future methodology for analyzing the stability of OPVs (and other new solar cell technologies) can be carried out. This presents great potential if this or similar methodologies can be used to analyze more OPV materials (interfaces, electrodes) and fabrication methods (printing or evaporation techniques) and correlate these with the effect on device lifetime. This, and similar approaches, can clearly close the well-known gap observed between laboratory-scale 
OPVs and industrial-scale devices, and can pave the way to overcome the major difficulties in crossing the internationally recognized "Valley of Death" for OPVs, defined as the period of transition when a developing technology is seen as promising, but is too new to validate its commercial potential and unable to attract the necessary funding for its continued development.

Dye sensitized and perovskite solar cells may be considered to be in a similar situation even though at differing levels of maturity. Common aim of all these technologies under development is to understand what induces changes foremost in the electrical properties of the PV devices but also to the mechanical, the physical and chemical properties of the various layers and interfaces under ambient factors such as light, temperature, humidity and oxygen. This is done with a combination of electrical, optical, morphological, mechanical and chemically-sensitive techniques and associated modelling. Compared to OPV, the perovskite field is still in its infancy ${ }^{[15]}$ but many considerations of the OPV can be applied to this new field. There are significant differences, though. Most notable is the chemical stability of the perovskite ${ }^{[16]}$ which can decompose into $\mathrm{PbI}_{2}$ and/or other components which are detrimental to the stability of output power. The photoactive layer is susceptible to moisture, oxygen, UV light and temperature with water being a major culprit for catalyzing decomposition. ${ }^{[17]}$ Whereas perovskite devices do not typically contain a photoactive blend system as used in OPV, the morphological and crystalline structure of the perovskite layer ${ }^{[18]}$ does play a huge role in the performance and stability of these devices. The top hole conductor also has a strong bearing on performance both at the cell level ${ }^{[19]}$ and at the module level. ${ }^{[20]}$ Perovskite solar cells can be found in two main architectures that both deliver high efficiencies: with and without a mesoporous scaffold (typically made of titania or alumina). Early signs ${ }^{[21]}$ show that the presence of a nanostructured scaffold can have a significant positive effect on device stability. ${ }^{[22]}$ Furthermore, perovskites have been shown to suffer from measurement induced hysteresis, ${ }^{[23]}$ which needs also to be considered when designing measurement and stability 
protocols for this type of device. Recently, outdoor field data have also been reported ${ }^{[24]}$ on hole-conductor-free PSCs based on a triple-layer architecture employing carbon as a back contact as well as heat exposure during 3 months at $80-85^{\circ} \mathrm{C}$, which are encouraging. ${ }^{[25]}$ Dye solar cells ${ }^{[26]}$ are electrochemical devices so the differences regarding stability are even more substantial. ${ }^{[27]}$ The glaring one is the presence of a liquid electrolyte. It needs to be contained inside the cell chamber which puts an onus on effective encapsulation, which not only needs to keep oxygen and moisture out (since these can cause chemical changes to the electrolyte together with UV light ${ }^{[28]}$ and the dye or its detachment, which makes hydrophobic dyes more stable $\mathrm{e}^{[29]}$ ), but also keep the corrosive electrolyte from seeping out (this limits the current sustaining capabilities of the cells and can corrode the silver contacts of a module). Thus effective encapsulants and barriers are required together with electrolytes with high boiling point solvents ${ }^{[30]}$ and stabilizing additives. ${ }^{[31]}$ The task is more severe when developing devices on flexible substrates. ${ }^{[32]}$ Solid or quasi solid state DSSCs with polymeric hole transporters or gel electrolytes have also been developed to increase stability. ${ }^{[33]}$

Electrochemical reactions occurring in reverse biased dye solar cells ${ }^{[34]}$ (as would happen to a shaded cell in a module) can also lead to device failure if severe. ${ }^{[35]}$ Thus stability is achieved via a combination of stable materials and effective encapsulation.

\subsection{Focus of industrial studies}

Durability, safety, quality, and reliability of the PV modules and systems are of paramount importance to manufacturers as well as the whole PV value chain. Product failure or sub-par performance can translate into poor reputation and commercial loss, which makes stakeholders especially attentive to these issues. ${ }^{[36]}$ As outlined previously, for manufacturers wishing to qualify their thin film PV modules, testing currently mainly goes through the IEC 61646 sequences. The IEC 61646 protocol clearly states its objective in the first page, which "is to determine the electrical and thermal 
characteristics of the module and to show, as far as possible within reasonable constraints of cost and time, that the module is capable of withstanding prolonged exposure in climates described in the scope."

It is interesting to understand the failure rates for these tests before analyzing how these translate or find correspondence in outdoor field tests. Figure 6 shows failure rates related to 2000 certification projects for IEC 61215 and IEC 61646 type approval tests for the years 2002 to 2012 carried out by TÜV Rheinland. ${ }^{[37]}$ A certification project is based on either IEC 61215 or IEC 61646 protocols, together with the safety IEC 61730 qualification. Two thirds $(67 \%)$ of the projects failed the criteria for new thin-film modules in 2007 , likely a result of many start-ups or companies newly entering the thin-film PV market using testing houses to screen new product designs during development or their finished product for the first time. As a result of manufacturers learning to better fulfil the IEC standards when constructing new module types as well as on-going developments in the market, the failure rates decreased significantly over the years. Remarkably, by 2012 the rate of failed IEC projects had dropped to $10 \%$.

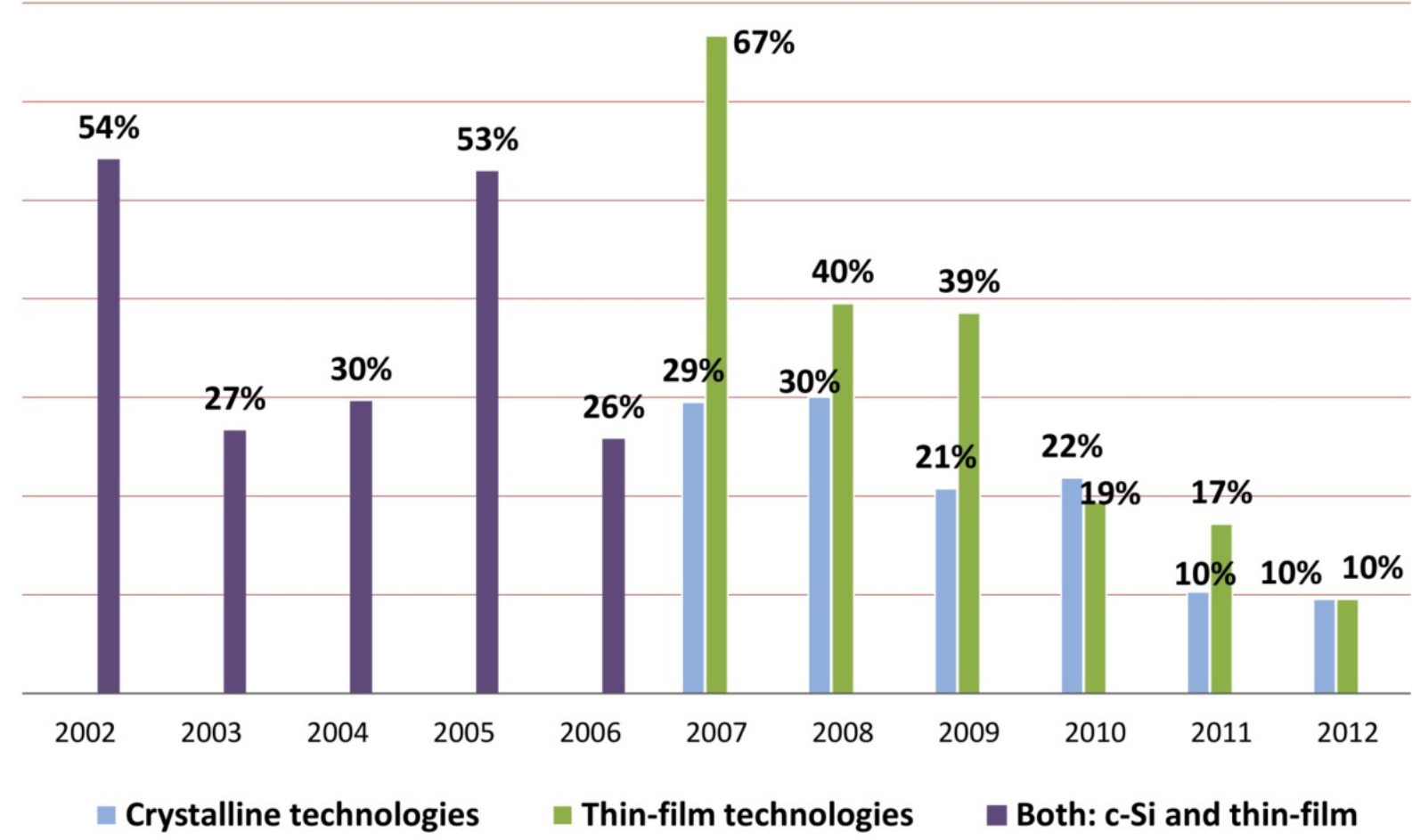


Figure 6: Annual percentages of IEC projects with at least 1 module test failure compared to the sum of all IEC projects conducted by TÜV Rheinland regarding both crystalline and thin film technologies. Failure rates are related to 2000 certification projects for IEC 61215 and IEC 61646 type approval tests for the years 2002 to 2012. ${ }^{[37]}$

The trend of Figure 1 is indeed promising in showing how manufacturers are improving in the production of module designs that are able to pass the IEC tests. Qualification tests, however, have their limitations. This is immediately apparent from the text of the IEC 61646 protocol which, after stating its objective (see above), immediately adds an important sentence: "The actual life expectancy of modules so qualified will depend on their design, their environment and the conditions under which they are operated."

For this reason, outdoor field testing has thus played "a vital role in quantifying long-term behavior and lifetime", representing the typical operating environment for PV systems, and the only way to correlate indoor accelerated testing to outdoor results. ${ }^{[38]}$ Figure 7 shows the degradation rates of thin film PV based on field tests reported in the literature during the last 40 years summarized by Jordan et al. ${ }^{[38]}$ The median degradation rate was $1.0 \%$ /year whilst the average was $1.5 \% / y e a r$. These values were roughly double those found for crystalline silicon, for which the median was $0.5 \% /$ year and the average $0.7 \% / y e a r$. Similar results were obtained by another study, for which the average annual performance loss rate of the thin-film systems was $1.78 \% / y e a r .{ }^{[39]}$ A significant decrease in degradation rates for post-2000 installations can be noted compared to the pre-2000 counterparts although they are statistically closer to $1 \%$ /year than to the safe $0.5 \%$ /year necessary to meet the 25 -year commercial warranties. ${ }^{[38]}$ Thus, although these statistics show a positive trend, there is room for continued improvement especially considering the fact that, in the future, the aim is to extend the lifetime of PV systems beyond the 25 year mark. ${ }^{[40]}$ 


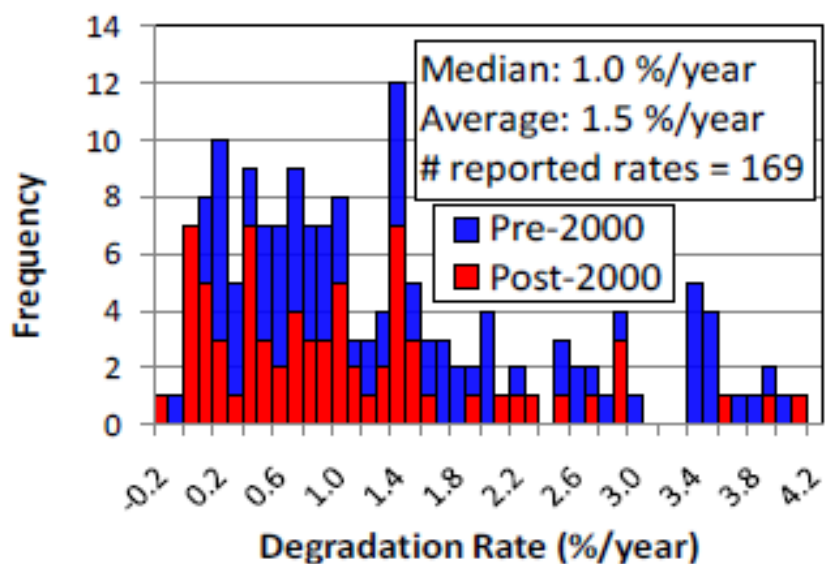

Figure 7: Histogram of reported degradation rates for all degradation rates for thin-film technologies, color-coded by date of installation into pre-2000 and post-2000. Median, average, and number of reported rates are also indicated. ${ }^{[38]}$

The modules that have successfully passed the IEC qualifications "are much more likely to survive in the field" as testified by a number of reports with very low field failures and warranty returns and excellent reliability, mostly due to such testing. ${ }^{[41]}$. However, recent studies on degradation/failure modes of PV modules have shown that even the qualified modules sometimes fail or degrade more rapidly than expected. ${ }^{[42]}$ In fact, qualification tests do have their limitations. They are successful in identifying early infant mortality problems, but are neither designed nor sufficient for identifying and quantifying wear-out or degradation mechanisms, or to quantitatively predict lifetimes. Also, they are not applicable to all climates and system configurations. ${ }^{[43]}$ There has thus been a push for future qualification tests to be more quantitative,${ }^{[42 c]}$ as described in the next section. For reducing risk and strengthening the confidence in its products, the PV industry not only requires more predictive qualification tests but it has also been recommended that they employ bankability testing programs. ${ }^{[36]}$ "Bankable PV" is a result of consistent manufacturing (ensuring quality of the product over time), durable design, and system verification. ${ }^{[44]}$ Thus, a manufacturing quality assurance guideline for defining factory controls and guiding inspections is proposed to become a part of the future certification process together with the qualification tests on the modules. ${ }^{[41 b]}$

\subsection{Connections between scientific and industrial studies}


As an initial route to bridge the gap between the IEC qualification and longer term testing, harsher accelerated tests (i.e. significantly extending parameter ranges in individual tests) have been proposed. The introduction of new tests such as salt mist and ammonia corrosive testing has also helped in determining whether a product can withstand variations in local environmental conditions across the globe. Hence, initiating field tests in specific climates is important. $^{[43 b]}$

The push of the industry and experts in the field goes towards designing more quantitative accelerated tests which can estimate lifetime values for different deployments. The availability of comparative test protocols that can differentiate PV modules according to their durability is desirable. "A very important opportunity is to design future test standards to facilitate learning about lifetime prediction." which can also deliver a rating system documenting the relative durability of the module to each type of stress. ${ }^{[41 \mathrm{~b}]}$ Such an effort would require extensive coordination and participation from not only PV manufacturers and testing houses, but also research laboratories and academia. This would improve the standard qualifications so that they are able to better predict long-term performance for different applications and climates. ${ }^{[43 \mathrm{~b}]}$ The process of designing new standards represents a tremendous opportunity for scientific research to design tests and analyze data in order to understand the science behind the observed degradation and failure modes and to come up with tests which are more quantitatively predictive.

\section{The burn-in effect}

\subsection{Definition of burn-in}

"Burn-in" is generally considered to be the initial fast decay of device performance often found specifically, but not exclusively, in polymer-based organic solar cells. The time scale of the burn-in has been observed to range from several tens of hours ${ }^{[45]}$, over a few hundred hours ${ }^{[46]}$ to a few thousand hours. ${ }^{[47]}$ It is a prerequisite that after the initial burn-in, the solar cell performance becomes more stable and decays at a slower rate. Otherwise, if the 
performance would decay directly to zero, the device would simply "burn-out". Whereas the burn-in should be normally governed by intrinsic effects that are inherently related to the materials' properties, impurities, blend morphology and the layer stack, a burn-out most certainly will be connected to extrinsic effects, such as (photo-)oxidation of materials.

\subsection{Analytical model to describe degradation and lifetime}

Historically, the magnitude of the burn-in time has not been clearly and unambiguously defined but is usually "arbitrarily defined by the user" via closely analyzing the decay by eye. ${ }^{[4]}$ As this is a rather subjective approach, the burn-in time is not a well-defined parameter. Here we would like to suggest the application of a biexponential function as a model which allows the description of time-dependent changes in solar cell parameters and yields a straightforward description of an objective burn-in time. ${ }^{[7]}$ In fact this approach has been used in the past to fit performance decay, ${ }^{[48]}$ but to date it is not yet well accepted among researchers, and here we will go one step further in defining the model for extracting device lifetime. According to the biexponential fit of the device efficiency over time, the most commonly observed degradation behavior can be described:

$$
\eta(t)=A \cdot \mathrm{e}^{-t / \tau_{1}}+B \cdot \mathrm{e}^{-t / \tau_{2}}
$$

Here, $\eta$ is the device efficiency, but in principle it can also be any other photovoltaic parameter which follows a more complex biexponential trend as well. $A$ and $B$ are the scaling parameters for each exponential function. The sum of $A$ and $B$ should either be equal to the efficiency at the starting time $t \equiv 0$ or unity, depending on whether an absolute or normalized curve is fitted. $\tau_{1}$ and $\tau_{2}$ are the respective time constants of the exponential decays.

In the following, we will provide an example reasoning the application of this model for fitting the performance decay. It allows the evaluation of individual degradation behaviors of the photovoltaic parameters, which can then be combined to obtain the PCE, i.e. as the product of short circuit current density $\left(\mathrm{J}_{\mathrm{SC}}\right), \mathrm{V}_{\mathrm{OC}}$ and fill factor $(\mathrm{FF})$ divided by the incident light irradiance: 
$\eta(t)=\frac{F F(t) \cdot J_{S C}(t) \cdot V_{O C}(t)}{P_{i n}}$
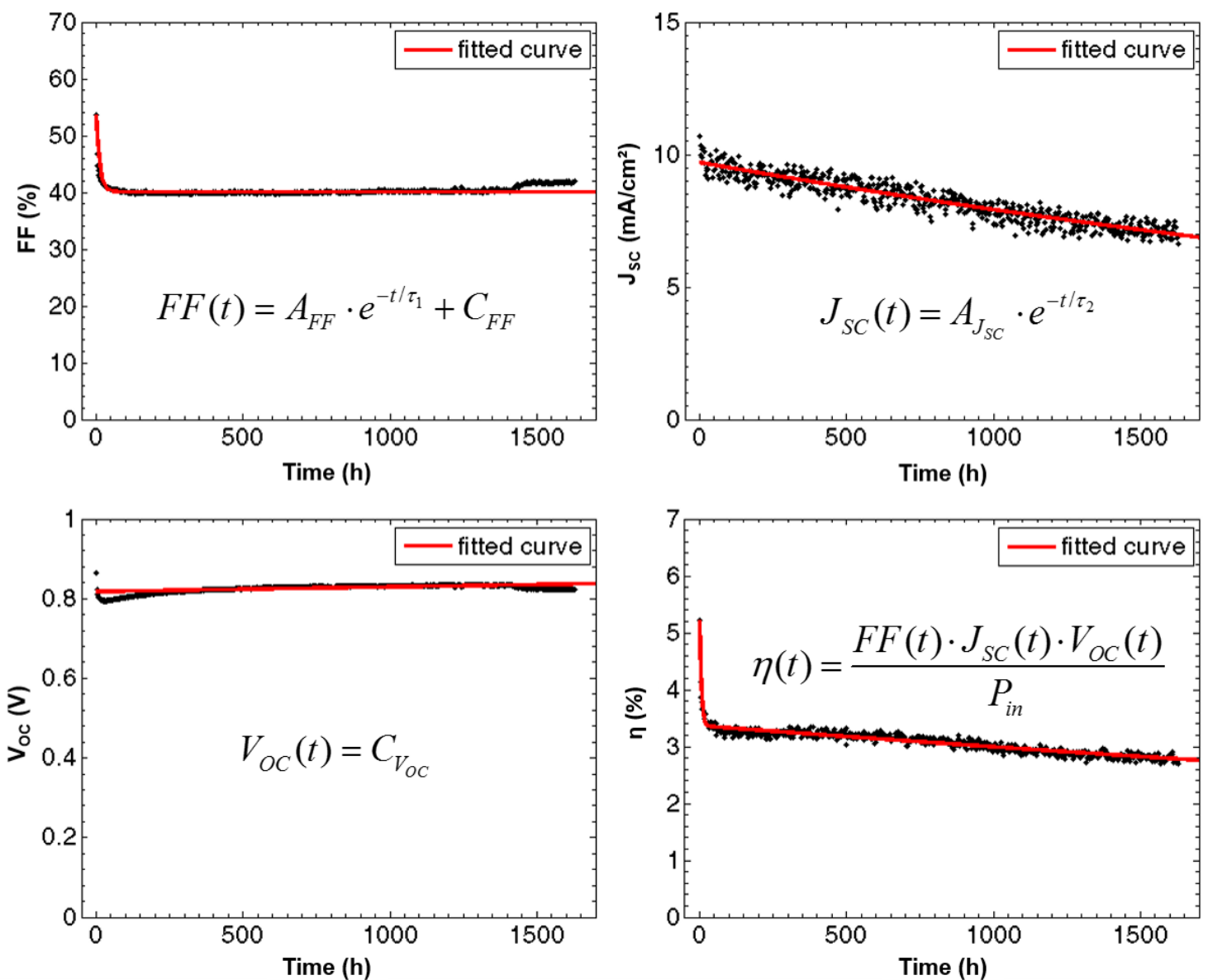

Figure 8: Time progression of photovoltaic parameters of a device stressed in an ISOS-L-1 setup (black dots), curves fitted to the parameters are represented by the red lines. Note that the minor changes occurring for the FF and $V_{\text {OC }}$ at about 1400 hours are due to a temperature change and do not affect the $\eta$.

In a first step, different fits for the time dependence of each photovoltaic parameter have been applied as shown in Figure 8. In this example, FF exhibited an exponential decay with a constant offset, a simple exponential fit was used for $\mathrm{J}_{\mathrm{SC}}$ and $\mathrm{V}_{\mathrm{OC}}$ was approximately constant. This yields the following fitting functions:

$$
\begin{aligned}
& F F(t)=A_{F F} \cdot e^{-t / \tau_{1}}+C_{F F} \\
& J_{S C}(t)=A_{J_{S C}} \cdot e^{-t / \tau_{2}} \\
& V_{O C}(t)=C_{V_{O C}}
\end{aligned}
$$


Table 4: Fitting parameters gained from fitting the photovoltaic parameters shown in Figure 2 according to Equations (3) to (5).

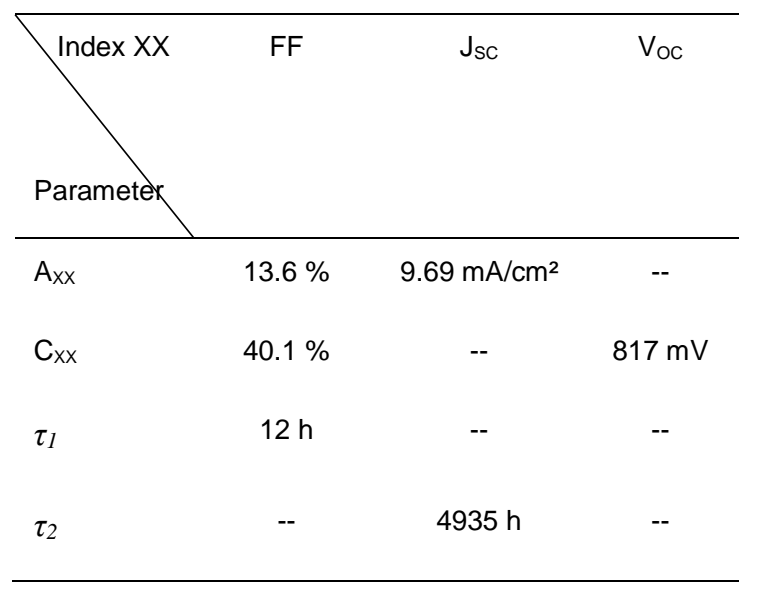

The respective parameters gained from fitting can be seen in Table 4. It is evident, both from these values and the graphs in Figure 8, that FF decays most rapidly out of all parameters during the burn-in period and that the loss in $\mathrm{J}_{\mathrm{SC}}$ is primarily responsible for the long-term loss in efficiency. This illustrates the potential of such a model to identify which photovoltaic parameters are directly related to overall performance loss. To yield an expression for the efficiency $\eta$, Equations (3) through (5) are then simply multiplied according to Equation (2), and by assuming that $\tau_{1}<<\tau_{2}$, the calculation indeed results in a biexponential function as described in Equation (1):

$$
\begin{aligned}
P C E(t) & =\frac{\left(A_{F F} \cdot \mathrm{e}^{-t / \tau_{1}}+C_{F F}\right) \cdot A_{J_{S C}} \cdot \mathrm{e}^{-t / \tau_{2}} \cdot C_{V_{O C}}}{P_{i n}} \\
& =\frac{A_{J_{S C}} \cdot C_{V_{O C}} \cdot A_{F F}}{P_{i n}} \cdot \mathrm{e}^{-t / \tau_{2}} \cdot \mathrm{e}^{-t / \tau_{1}}+\frac{A_{J_{S C}} \cdot C_{V_{O C}} \cdot C_{F F}}{P_{i n}} \cdot \mathrm{e}^{-t / \tau_{2}} \\
& \approx A \quad A \quad \cdot \mathrm{e}^{-t / \tau_{1}}+B \quad \cdot \mathrm{e}^{-t / \tau_{2}}
\end{aligned}
$$

Table 5: Comparison between fitting parameters calculated according to (6) and acquired from a biexponential fit of the $\eta$.

\begin{tabular}{lcc}
\hline Parameter & Calculated & Direct fit \\
\hline $\mathrm{A}$ & $1.08 \%$ & $1.86 \%$ \\
$\mathrm{~B}$ & $3.17 \%$ & $3.36 \%$ \\
$\tau_{1}$ & $12 \mathrm{~h}$ & $6 \mathrm{~h}$ \\
$\tau_{2}$ & $4935 \mathrm{~h}$ & $8538 \mathrm{~h}$ \\
\hline
\end{tabular}


With this, the fitting parameters for the temporal development of the efficiency $\eta$ namely $A, B$, $\tau_{1}$ and $\tau_{2}$ can be principally derived from fits of the individual photovoltaic parameters. The calculated values are represented in Table 5, in comparison with values gained from a direct biexponential fit of the efficiency decay. We note the agreement is only within a factor of two specifically for parameter A and the time constants. One reason for this can be the approximation of $\mathrm{V}_{\mathrm{OC}}$ as a constant, as this disregards the (slight) very fast voltage drop occurring in the beginning. However, this example can be used for illustrative purposes as the proper orders of magnitude are maintained.

Depending on the absolute number of acting degradation effects, manifesting themselves within more or less complicated temporal progressions of the individual photovoltaic parameters, the overall progression of the power conversion efficiency may span the range between linear, mono-, bi- or even tri-exponential decaying behavior. Respectively, the less complicated the temporal dependency of the efficiency is, the fewer simultaneously acting degradation effects are present. If the temporal dependency of each photovoltaic parameter is evaluated individually and the stress conditions are varied in addition, an improved assignment of photovoltaic parameter decays to certain degradation effects can be obtained and stabilization efforts can specifically be tackled.

Based on the knowledge of the main responsible stress factor for the long-term decay, and its manifestation within certain photovoltaic parameters, either the prevention of this stress factor or a lower sensitivity of the material system respectively layer stack by constructive stabilization efforts may ultimately yield longer operational lifetimes.

\section{Analytical determination of the burn-in time:}

Such a biexponential function directly applied to the efficiency decay can then be used to evaluate the burn-in time of fitted degradation curves as follows: Without loss of generality, the first exponent of the fitting function (1) may represent the much faster decay assigned to 
the burn-in $\left(\tau_{1}<<\tau_{2}\right)$. This means that during the initial time regime of degradation, the first exponential is mainly responsible for loss in efficiency.

We can now define that the burn-in has ended when this fast decaying exponential has reached a negligible $1 \%$ of its starting value:

$$
A \cdot \mathrm{e}^{-T_{S} / \tau_{1}}=0.01 \cdot A
$$

the burn-in time $T_{S}$ can be calculated as follows:

$T_{S}=-\tau_{1} \cdot \ln 0.01$

Once the burn-in time $T_{S}$ is defined, this enables the extraction of additional useful parameters such as the operative lifetime of the device after stabilization, $T_{S 80}$, from

$$
0.8 \cdot \eta\left(T_{S}\right)=\eta\left(T_{S 80}\right)
$$

(in accordance with Reese et al. ${ }^{[4]}$ ). Assuming that the first exponential is negligible compared to the second exponential after burn-in has ended $(0.01 \cdot A \ll B)$, eq. (9) - in conjunction with (1) - is simplified to

$$
0.8 \cdot B \cdot \mathrm{e}^{-T_{S} / \tau_{2}}=B \cdot \mathrm{e}^{-T_{S 80} / \tau_{2}} .
$$

Therefore, the operative lifetime $T_{S 80}$ can be calculated via:

$$
T_{S 80}=-\tau_{2} \cdot \ln 0.8+T_{S}
$$

For gaining practical information about the energy delivered by the solar cell over the nominal lifetime $T_{S 80}$, we define as a figure of merit, the "lifetime energy yield" (LEY): the LEY of solar cells can be calculated by integrating fitted biexponential functions over their operational lifetime up to $T_{S 80}$ and multiplying this value by the assumed incident intensity of $1 \mathrm{~kW} / \mathrm{m}^{2}$ under standard conditions (compare with $\left.{ }^{[7,49]}\right) . L E Y=\int_{t=0}^{T_{S 80}} \eta(t) d t \cdot 1 \mathrm{~kW} / \mathrm{m}^{2}$. 
This parameter allows the evaluation of the total energy yield over the nominal lifetime of a photovoltaic device and thus combines the progression of efficiency over time and the lifetime itself in a single handy parameter. For visualization, all derived parameters are shown in Figure 9 for the example degradation curve discussed above. We obtain a burn-in time $\mathrm{T}_{\mathrm{S}}$ of $26 \mathrm{~h}, \mathrm{a} \mathrm{T}_{\mathrm{s} 80}$ of $1931 \mathrm{~h}$ and a LEY of $58 \mathrm{kWh} / \mathrm{m}^{2}$.

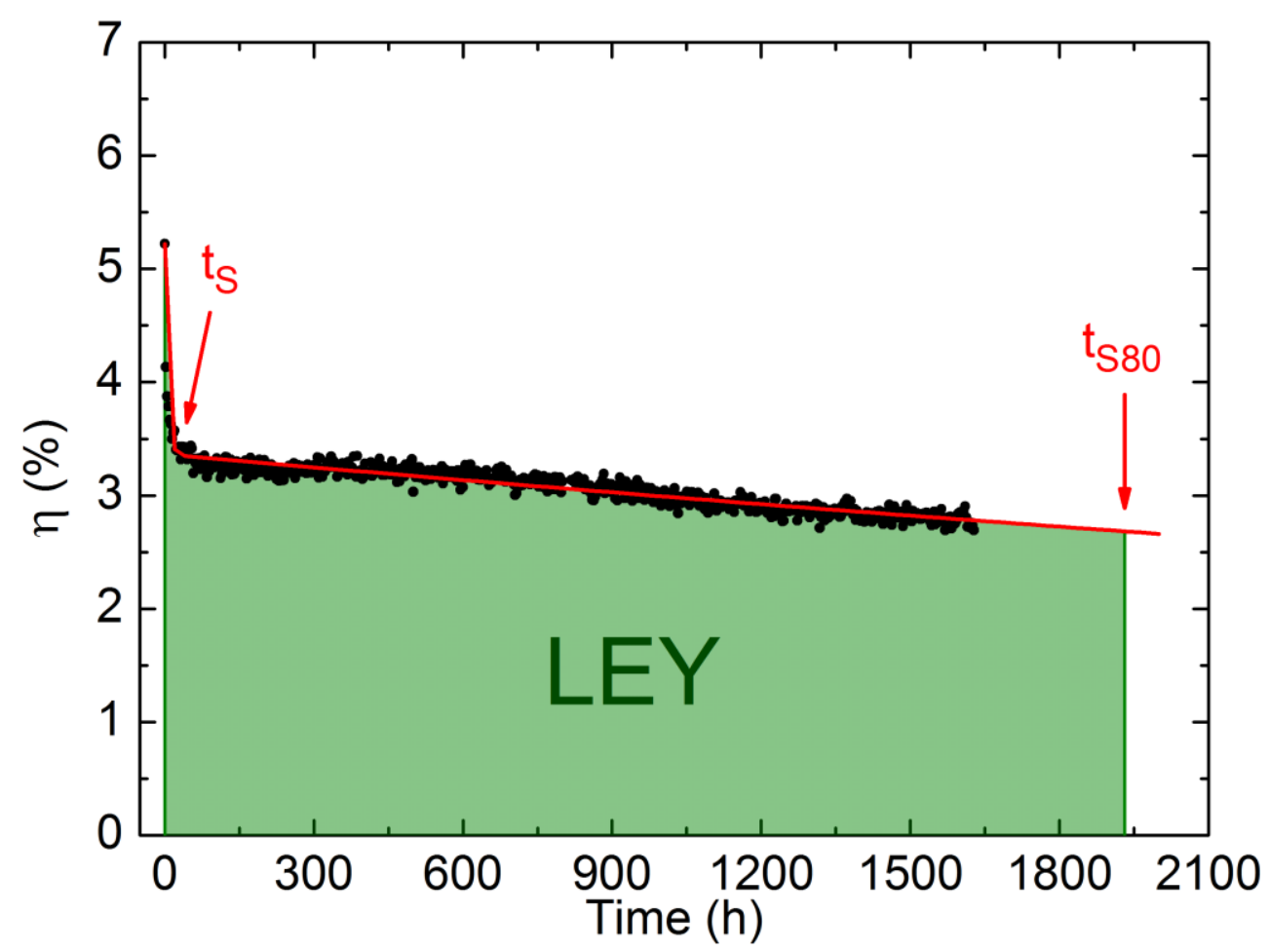

Figure 9: Example degradation curve with parameters calculated from a biexponential fit, marked: burnin time $T_{\mathrm{s}}$, operational lifetime $\mathbf{T}_{\mathbf{S 8 0}}$ and lifetime energy yield (LEY).

\subsection{Known and suspected stress factors causing a burn-in in OPV}

Though not all causes of the burn-in are known, many of the factors that strongly influence the burn-in behavior of polymer solar cell devices have been revealed. It should be stated here that burn-in can occur in all photovoltaic parameters, however, generally the open circuit voltage is only marginally affected. Key stress factors responsible for burn-in are either remaining impurities within the photoactive layer, light and heat, whereas directly currentinduced effects such as electrochemical reactions at one electrode may play a minor role. 
Light is one key component in enabling the fast initial decay of device performance. ${ }^{[11,50]}$ Light enables photo-induced reactions within the active layer, such as the formation of subbandgap states. These trap states can enhance loss processes like Shockley-Read-Hall recombination, thus reducing hole mobility and building up a space-charge within the traps. This leads to a reduction of the electric field responsible for the extraction of charge carriers. $^{[50]}$

Additionally, it is possible that residual oxygen within the active layer photo-oxidizes the polymer and thus reduces device efficiency, ${ }^{[45 b, 51]}{ }^{[52]}$ though Mateker et al. have suggested, based on a calculation, that this is an unlikely cause in the case of encapsulated PCDTBT:PC $70 \mathrm{BM}$ solar cells as the concentration of residual oxygen in the photoactive layer is usually lower than what would be needed to affect device performance as significantly as is observed during burn-in. ${ }^{[47 b]}$ However, in case the devices are exposed to air during preparation, such effects cannot be prevented. ${ }^{[45 b]}$ It could also be shown that the oxidation of not only the polymer, but of PCBM might be a relevant factor in promoting burn-in-like behavior. ${ }^{[53]}$

Generally, the effects of burn-in seem to stem from reactions or morphological changes within the photoactive layer rather than being dependent on electrode materials. For instance, using polymers with higher crystallinity reduces the loss in open-circuit voltage observed during burn-in due to reduced photo-oxidation and a smaller impact of charge carrier recombination in degradation-induced traps. ${ }^{[54]}$ Also, the impact of the burn-in on the different photovoltaic parameters is highly dependent on the material system used in the photoactive layer: While $\mathrm{P} 3 \mathrm{HT}: \mathrm{PC}_{60} \mathrm{BM}$ devices mostly show a decrease of short circuit current and open circuit voltage, solar cells using PCDTBT:PC $70 \mathrm{BM}$ show mostly a decline in the fill factor during the first hours of operation. ${ }^{[46]}$

Since thermal stress has been shown to induce effects such as trap formation ${ }^{[50]}$ and interfacial segregation, ${ }^{[55]}$ this factor may play an important role in the improved understanding of burn- 
in. Furthermore it should not be disregarded that stress induced via IV-measurements themselves can alter the course of the burn-in during degradation experiments. ${ }^{[7]}$ Depending on the voltage ranges used to characterize the solar cells, increased currents introduce more (thermal) energy into the devices, thus aiding the above mentioned mechanisms or fueling morphological rearrangements in the photoactive layer that decrease device performance. ${ }^{[55]}$ This underlines the importance for reporting all experimental stress conditions as well as all photovoltaic parameters (as described in section 3) in order to further understand the underlying mechanisms.

The fact that the burn-in can be influenced via the active layer morphology is further reinforced by the observation that photo-induced dimerization of the fullerenes within the blend can already be beneficial for device stability in the first hours of degradation. ${ }^{[56]}$ Additionally, it has been shown that the composition of the polymer, in terms of molecular weight distribution, highly influences the burn-in phase. ${ }^{[57]}$ Solar cells with little to no amount of short-chain PCDTBT showed a strongly reduced decay, which was attributed to a significantly lower trap density. In agreement with earlier studies, ${ }^{[55 a, 58]}$ this trap formation may have to be assigned to morphological changes within the photoactive blend, indicating that lower molecular weight fractions allow more morphological rearrangements either within the polymer phase itself or due to increased fullerene diffusion and, hence, phase separation. The intensity of the burn-in can thus be notably lowered by use of higher molecular weight fractions of donor polymers and a stabilization of the active layer morphology, e.g. by dimerization of fullerenes or functionalization of polymer side chains. ${ }^{[59]}$ Whether continuous phase separation or phase, respectively interfacial, segregation within the photoactive bulk heterojunction should be accounted for in determining burn-in shall not be discussed here in detail, as this may strongly depend on the extent to which phase separation occurs and whether equilibrium can be reached. Continuous phase separation will contribute to long term 
degradation effects, whereas in case equilibrium is reached, it may only account for the burnin. However, more studies are required at present date to address these questions properly.

\subsection{Suggested further studies to isolate the effects of burn-in in OPV}

As many different factors can cause the observed burn-in, understanding their impact on degradation and how they are correlated is important in order to potentially reduce the significance of the burn-in on the performance of organic photovoltaic devices. For this, further studies need to be conducted isolating and analyzing the influence of each factor related to the burn-in.

As light and temperature play key roles, variations in light intensity and spectral distribution as well as storage temperature should be investigated. By careful comparison of devices aged under different temperatures in the dark and in the light, a better discrimination between the impact of each stress factor may be obtained. Additionally, high energy UV-light in the spectrum is expected to have a critical impact on the burn-in.

Furthermore, by varying the atmosphere under which the cells are encapsulated and degraded and by studying reference non-encapsulated devices, the impact of oxygen on the burn-in behavior can be more clearly determined.

Using the lessons learned from specific material systems, directed attempts for constructive stabilization should be conducted. The goal is to minimize both short and long term degradation so that stabilized performances can be obtained.

\section{Long-term degradation effects}

\subsection{Definition of long-term degradation effects}

Long term degradation effects dominate the performance loss after the burn-in period has ended. Depending on the nature of the degradation mechanism, principally linear or exponential decays are possible. Furthermore it is important to discriminate between intrinsic and extrinsic effects, since the latter will be controlled by the quality of the encapsulation, whereas the former is an inherent property of the material system and the layer stack used. 
Technically, long-term degradation rates can be quantified - at least in the case of a linear decay - by a certain relative percentage loss occurring within one year of application or, when accelerated lifetime tests are applied, by a percentage loss during 1000 hours of continuous operation. In middle Europe about 1000 hours of sun shine are estimated to occur during one

year, so these values can be, with some limitations, approximated as equal. ${ }^{[47 \mathrm{~b}]}$ Values around $1 \%$ relative loss per 1000 hours of continuous operation or per year are considered good values, as they are comparable to other thin-film photovoltaic technologies (as shown in section 4.2 of this article) and indicate application lifetimes beyond 20 years.

However, care has to be taken when extrapolating operational lifetimes based on a linear regression, as it cannot be taken for granted that the sealing will not fail during the extrapolation. This issue is especially important for products ready for commercialization and it must be ensured by additional characterizations that the sealing will withstand water and oxygen ingress for the projected application lifetime. Furthermore it should be ensured that the extrapolated operational lifetime does not exceed the testing time by an order of magnitude, as such values may be technically questionable.

From the underlying mechanisms, it can be assumed that any linear decay during degradation may scale with other linear stress parameters such as total amount of light absorption, total amount of heat dissipation or total amount of current passing through the device. However, as stated above, more complicated degradation effects, e.g. morphological changes inducing photocurrent or fill factor losses, may result in more rapid, e.g. exponential, decay rates.

\subsection{Known and suspected factors for long-term degradation in OPV}

Contrary to silicon solar cells, organic photovoltaics (but also next generation hybrid solar cells like Hybrid Perovskite solar cells) are characterized by their versatility in terms of materials, device design and/or manufacturing processes. Therefore, an increased diversity of device types also increases the variability of degradation pathways and therefore ageing rates. For example, OPV devices with the same active layer mixture will degrade differently when 
fabricated in different architectures (inverted, normal), ${ }^{[9 b, 60]}$ or when different interface materials are employed. ${ }^{[10 \mathrm{~b}, 47 \mathrm{a}]}$ Variability in stability is also observed if the same solar cell is fabricated by different deposition techniques. ${ }^{[9 b, 11]}$ The fabrication of a set of identical solar cells delivering the same power conversion efficiency is not a warranty that the same degradation rates and pathways will take place, even when the same device materials for the same solar cell configuration are employed. ${ }^{[12]}$ However, this is clearly assigned to reproducibility issues during processing, and must be mitigated with further maturing of the production technology. The encapsulation method and the encapsulation quality also play an important issue in long-term stability. ${ }^{[9 a, 12 a]}$

The basic environmental factors affecting solar cell stability are oxygen, humidity, temperature and/or light. ${ }^{[61]}$ Whereas oxygen and humidity are extrinsic stress parameters, the temperature and light are understood as being of intrinsic nature, since they are inherent to solar cell operation. Probably the most known and early studied degradation mechanisms in OPVs are those induced by oxygen and/or water (humidity). ${ }^{[62]}$ Oxygen can be photoactivated by UV light and super oxides and hydrogen peroxide can be formed which may degrade organic semiconductors in the device. The exposure to ambient air is also known to invoke the diffusion of oxygen and water into the solar cells degrading organic materials. Although very low percentage of humidity (below 30\%) can be acceptable for solar cell testing without encapsulation, the presence of oxygen will limit device lifetime. Thus, encapsulation is always required for accurate stability analyses.

Light can affect device degradation depending on its intensity, spectral distribution, and whether continuous or intermittent illumination is applied. ${ }^{[46,63]}$ The effect of UV light is especially harmful for any organic matter and organic solar cells are no exception. UV light can also photo-activate semiconductor oxides applied as barrier layers in the devices resulting in the degradation of the organic/oxide interface. ${ }^{[64]}$ When studying light induced degradation, it may be desirable to use light intensities beyond one sun in order to accelerate the effects. 
However, even illumination at one sun is enough to increase solar cell temperature considerably, an effect that will increase largely for higher light intensities. Hence it can be challenging to distinguish between light- and temperature-induced degradation effects under such conditions. However, via proper design of a cooled sample holder, temperature can be regained as independent parameter, ${ }^{[21,65]}$ allowing to isolate the effects of light on stability. Temperature is an important parameter to consider in stability tests, it can also be used to determine acceleration factors. ${ }^{[61 \mathrm{a}, 61 \mathrm{~b}, 66]}$ Based on the assumption that the degradation process under study follows an Arrhenius type model with an exponential rate equation, a decay rate $\mathrm{k}$ has been defined to describe changes in device performance as a function of temperature: ${ }^{[67]}$ $k=A \cdot \mathrm{e}^{\left(\frac{-E_{a}}{R T}\right)}$

where $E_{a}$ is the activation energy for the process; $R$ the gas constant; $T$ the temperature and $A$ a pre-exponential factor. The expression for the acceleration factor AF obtained between two different temperatures $\left(T_{1}\right.$ and $\left.T_{2}\right)$ is then given by:

$$
A F=\mathrm{e}^{\left[\frac{E_{a}}{R}\left(\frac{1}{T_{1}}-\frac{1}{T_{2}}\right)\right]}
$$

If we consider also two different irradiances $\left(\mathrm{I}_{1}\right.$ and $\left.\mathrm{I}_{2}\right)$, which have a linear effect as stated above, we obtain:

$$
A F=\left(\frac{I_{1}}{I_{2}}\right) \cdot \mathrm{e}^{\left[\frac{E_{a}}{R}\left(\frac{1}{T_{1}}-\frac{1}{T_{2}}\right)\right]}
$$

This model can provide information on the rate of the degradation of OPVs induced by either temperature or by light and temperature simultaneously, in the presence or absence of oxygen. The degradation rate is related to mechanisms such as macromolecular chain scission and crosslinking reactions, discoloration and bleaching of aromatic and vinyl polymers. These mechanisms account for most of the degradation modes observed in OPV devices, including encapsulated devices. Nevertheless, the model does not indicate additional accelerated degradation arising from the individual or combined effects of water/humidity, generated 
photocurrent, temperature changes or the mechanical stresses resulting from exterior factors such as wind, snow or hail. ${ }^{[67 b]}$

The degradation factors described above depend on the materials used in the device: active layer, barrier layers (hole and electron transport layers), and electrodes (metal and transparent electrodes). The interface degradation between these different layers is also an important issue for the stability of the solar cell. ${ }^{[68]}$ Furthermore, as many studies clearly demonstrated and is mentioned above, temperature plays an important role for inducing morphological changes such as diffusion induced or domain coarsening controlled phase separation and interfacial segregation.

The active layer is likely where many degradation mechanisms take place. The photodegradation of a large number of organic molecules (polymers), with or without the presence of oxygen, was recently reported by Manceau et al., and a rule-of-thumb was suggested relating chemical structure with sensitivity to light-induced degradation ${ }^{[69]}$ (Figure 10). In general, donor groups with side chain are the most susceptible to degradation while the most stable are those without side chains. Moreover, the substitution of a carbon by a silicon atom for attachment also increases materials stability. ${ }^{[61 \mathrm{~b}, 69]}$ Another important issue is the morphological stability of the active layer which can be stabilized by the use of block copolymers or by cross linking. ${ }^{[70]}$ The use of block copolymers permits the design of materials which spontaneously form the desired ordered structure. ${ }^{[61 \mathrm{~b}, 71]}$ In this approach, the copolymers self-assemble depending on known types: coil-coil, coil-rod or rod-rod, where the coil is a flexible polymer and a rod is a rigid crystalline polymer. However, while this approach permits great variety of active material design, it presents the drawback that optimization of the structure and the final photovoltaic properties is difficult and time consuming. The use of crosslinking methods allow the incorporation of different active groups into the polymer structure and a stabilized structure can be created. ${ }^{[61 \mathrm{~b}, 70-71]}$ 
Crosslinking of the fullerene is also possible and in both cases thermal stability of the final active layer is improved. ${ }^{[71-72]}$

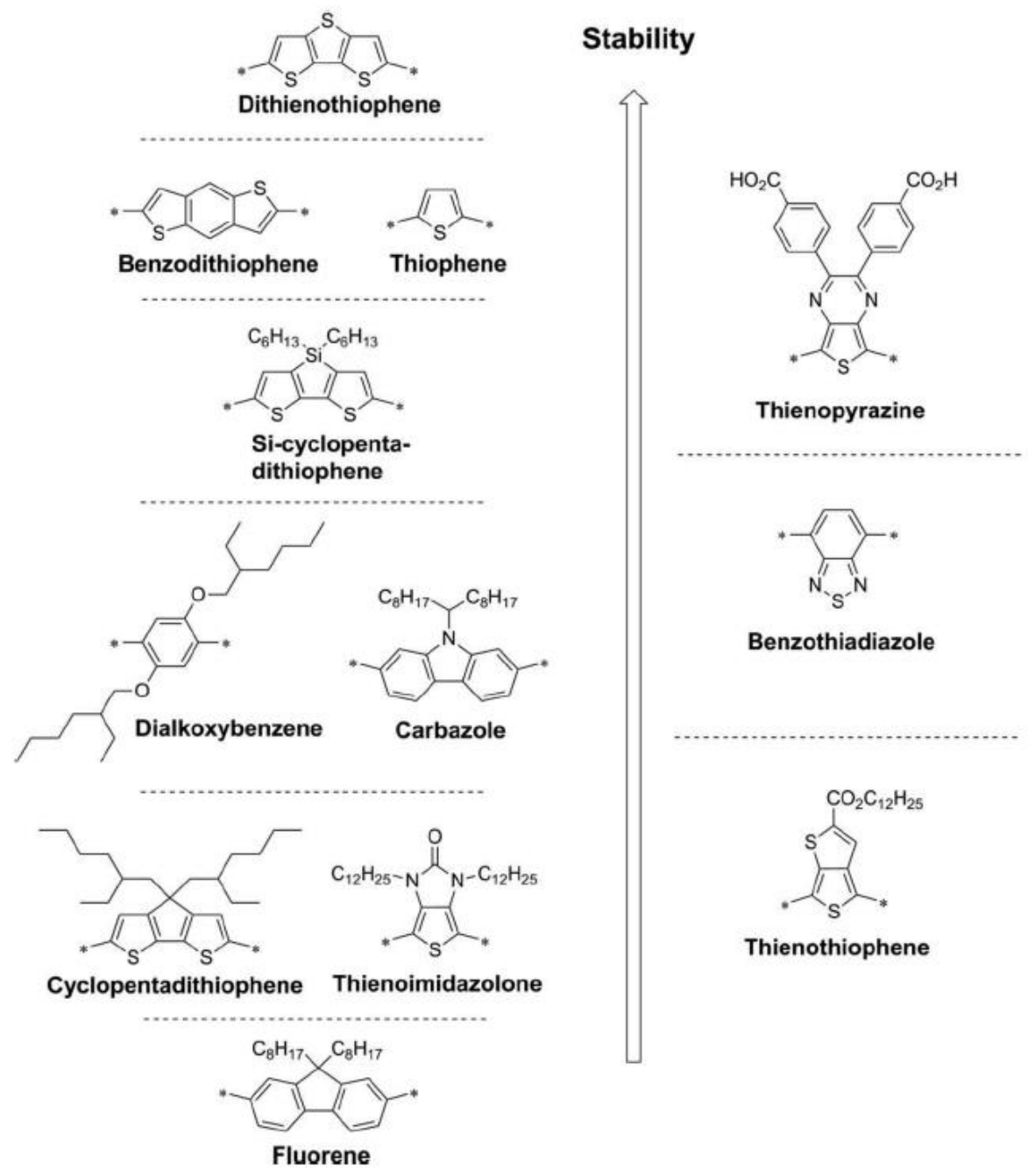

Figure 10: Rule-of-thumb photo-stability ranking of donor and acceptor monomers for OPV polymers. Reproduced with permission. Copyright Royal Soc. Chem. ${ }^{[69]}$

The metal and the transparent electrodes are also prone to degradation. Several materials within these two types of electrodes have been applied in OPVs: $\mathrm{Ag}, \mathrm{Al}, \mathrm{Ca}, \mathrm{Cu}$ for the back metal electrode and Indium and/or Fluor Tin Oxide for the transparent electrode. Nevertheless, due to the scarcity of some of these materials, mostly among the critical raw materials list of the $\mathrm{EU},{ }^{[73]}$ the need to replace transparent conducting electrodes made with ITO or reduce the use of metals such as Ag, is required. Thus, the technology is showing a tendency to move towards the application of ITO-free electrodes and the use of carbon-based 
back electrodes to replace metals. Concerning the pristine metals, the most important parameter is their work function. Metals with lower work function are prone to oxidation either by oxygen or also by water, ${ }^{[12 c, 45 a, 47 a, 74\{\text { Andreasen, } 2012 \# 9]}$ and hence their replacement by higher work function metals has been one major development target during the last decade. This has often been connected with a change in device architecture, switching from less stable "conventional" design to the so-called "inverted" architecture. ${ }^{[75]}$ Nowadays plenty of different interlayer materials have been developed in order to allow using metal electrodes with high work function to be applied for electron extraction. ${ }^{[76]}$

The charge transporting layers (hole and electron transport materials), as well as interfaces between charge transport layers and the active materials, are important components of OPVs that can yield enhanced solar cell stability. Several electron and hole transport layers are used in OPVs. The most studied hole transport layer is PEDOT:PSS, while $\mathrm{ZnO}$ has been established as the most promising electron transport layer due to its ease of fabrication and compatibility with solution processing printing methods. However, the hydrophilicity and hygroscopy of PEDOT:PSS is made responsible to be the cause of device failure and limitations in lifetime. Further suspected factors for degradation are the high acidity of water based PEDOT:PSS, ${ }^{[77]}$ giving rise to the development of water-free and neutral PEDOT:PSS dispersions. The use of oxide semiconductors as charge transporting layers have shown to deliver similar or enhance device efficiencies and enhanced lifetimes due to their reduced sensitivity to humidity. ${ }^{[47 a, 78]}$

\section{Catastrophic failures}

Typical consensus on what constitutes a "failure" in photovoltaic devices involves three descriptions: ${ }^{[43 b]}$

- catastrophic (no or negligible power output),

- power or efficiency loss beyond a defined value or limit,

- issues arising which render the device unsafe. 
From the perspective of different applications (e.g. building- or textile-integrated PV), other parameters which may not lead to failures in electrical or mechanical performance (e.g. aesthetic variations over time) may also be a consideration.

Manufacturers of PV modules offer warranties which include "repair, replace, or refund warranties" which cover defects in materials or workmanship and "Lost power replacement warranties". ${ }^{43 b]}$ Currently, manufacturers typically offer the latter type warranties over a time span of 20 to 25 years with threshold values in power output of $90 \%$ after 10 - 12 years and of $80 \%$ at the end of the warranty, corresponding to an average loss of $\leq 1 \%$ per year compared to the specified power output rating.

Ultimately the lifetime of a module remains application- and user-specific ${ }^{[79]}$ and thus is also technology dependent. For example, DSSCs have been shown to deliver impressive performance under low level or indoor light conditions. ${ }^{[80]}$ For this reason, commercial flexible DSSCs have entered the market to power electronic products indoors and the specified lifetimes for these are targeted to the less stressful environment ${ }^{[32,80 \mathrm{~b}]}$ compared to the outdoors, and are of the order of years rather than decades. These are similar to the user life spans of the commercial electronic products they are integrated in.

As described in the initial sections of this manuscript, protocols based on accelerated stress tests have been implemented both at the scientific level for organic PV for example ${ }^{[4]}$ and at the industrial/commercial readiness levels (e.g. the IEC standards 61646 standard). Whereas the ISOS protocols are not focused in the definition of failures, the IEC type tests are instead specifically aimed at qualifying a PV device and thus lay out pass/fail criteria in detail. Since new technologies such as organic, DSSCs and perovskite cells do not have their own criteria, the IEC 61646 'Thin-film terrestrial photovoltaic (PV) modules -design qualification and type approval', test can be clearly specifies what are considered failures. 
A module design is judged to have passed the qualification tests, and therefore, to be IEC type approved, if each sample meets the specific requirements of the individual tests and all of the following criteria (otherwise it is considered a failure): ${ }^{[1,79 a]}$

- power losses are within the maximum acceptable limits

- No open circuits occur during testing

- Dry and wet insulation tests remain within the set limits

- No major visual defects, such as cracks, bubbles, delamination or distortion are visible.

The criterion for the IEC 61215 used for c-Si modules and older versions of the IEC 61646 proscribed to maintain degradation of $\mathrm{P}_{\max }$ within $-5 \%$ after the single tests and $-8 \%$ after the sequence of tests. As specified in section 1, the current IEC 61646 test "no longer relies on meeting a plus/minus criterion before and after each test", but rather on reaching a stable power output during a light soaking test (subsequent to the completion of all test sequences), which needs to be no less than $90 \%$ of the minimum power rating specified by the manufacturer. "This eliminates the technology-specific preconditioning necessary to accurately measure the changes caused by the test."[1]

The types of failures that have been observed in PV modules are diverse as listed in various literature ${ }^{[43 a, 81]}$ and a number of common ones are summarized in Table 6 with their main cause (e.g. accelerated stress tests).

Table 6: Common failures in thin film PV modules and their main causes (e.g. IEC 41646 tests).

\begin{tabular}{|l|l|}
\hline Irradiation (mainly UV) & $\begin{array}{l}\text { Delamination, encapsulant degradation, } \\
\text { discoloration, photo-oxidation, degradation of } \\
\text { cell materials and contacts, light-induced } \\
\text { degradation, }\end{array}$ \\
\hline Damp heat tests and humidity & $\begin{array}{l}\text { Corrosion, delamination, encapsulant } \\
\text { degradation, chemical changes in cell } \\
\text { materials and their contacts, morphological }\end{array}$ \\
\hline
\end{tabular}




\begin{tabular}{|c|c|}
\hline & $\begin{array}{l}\text { changes, damage to external components (e.g. } \\
\text { junction boxes), edge sealant failure, } \\
\text { moisture induced degradation }\end{array}$ \\
\hline Temperature cycling & $\begin{array}{l}\text { Impact of different thermal expansion } \\
\text { coefficients, delamination, loss of } \\
\text { encapsulant adhesion, cracking, } \\
\text { interconnection breakage, delamination, } \\
\text { morphological changes in active layers, bond } \\
\text { failures, module open circuits leading to } \\
\text { arcing, damage to external components (e.g. } \\
\text { junction boxes and module connections), } \\
\text { annealing instabilities, }\end{array}$ \\
\hline Humidity Freeze & $\begin{array}{l}\text { Delamination, Inadequate edge deletion, } \\
\text { damage to external components (e.g. junction } \\
\text { boxes), degradation or breakage of } \\
\text { interconnections, corrosion }\end{array}$ \\
\hline Mechanical Tests & $\begin{array}{l}\text { Structural failures, broken glass, failures to } \\
\text { electrical connections and bonds }\end{array}$ \\
\hline Hot spot and bypass diode tests & $\begin{array}{l}\text { Hot spots induced degradation, shunts, } \\
\text { bypass inadequacy or failure, overheating }\end{array}$ \\
\hline Degradation due to currents and voltages & $\begin{array}{l}\text { Ion migration, changes in electronic structure } \\
\text { (traps etc.) of materials and interfaces, } \\
\text { electrochemical corrosion, potential-induced } \\
\text { degradation, }\end{array}$ \\
\hline Dry and Wet Insulation Resistance & $\begin{array}{l}\text { Delamination, Ground faults, Electro- } \\
\text { Corrosion, edge seal issues }\end{array}$ \\
\hline
\end{tabular}

Even though a few industrial outfits have claimed the successful passing of individual IEC 61646 tests for dye sensitized and organic $\mathrm{PV},{ }^{[3]}$ due to the immaturity of the field there has been no report on collection of statistics regarding failures for the new technologies being developed. Thus we must look at what causes major failures in commercial thin film PV modules (i.e. a-Si, CdTe, CIGS, see above). 
Figure 1 shows the breakdown of which tests caused projects carried out by TÜV Rheinland laboratory between 2006 and June 2013 to fail. 43\% of all thin-film module IEC 61646 approval tests failed during the four environmental tests which were carried out in the climate chambers (marked in blue in Figure 11), i.e. 50 and 200 cycles of thermal cycling, humidity freeze and the damp heat tests. The damp heat test in fact represented by far the single test that induced most failures $(22 \%){ }^{[37]}$

Scientific studies have shown the large role humidity plays in the degradation of OPV, DSSCs and perovskite solar cells, together with photo-oxidation, so there is no reason to believe that things will be substantially different for these new technologies aiming to compete in the PV field especially if developed or encapsulated on glass. For flexible PV, where porosity of plastic substrates makes the ingress of gasses more rapid for example, it is likely that these tests will be even more critical for organic or hybrid technologies. Thus, it is important that both the ISOS tests and the IEC tests be carried out more systematically to identify weak points where both the scientific and industrial community can contribute to bring stabilities to those required for applications and deliver devices which can be successfully qualified with the IEC standards until new standards are set for the future. As expressed by the IEA report, "The climate chamber tests are a good indication of the longevity to be expected, the quality of the materials, and the workmanship of the products". ${ }^{[37]}$ 


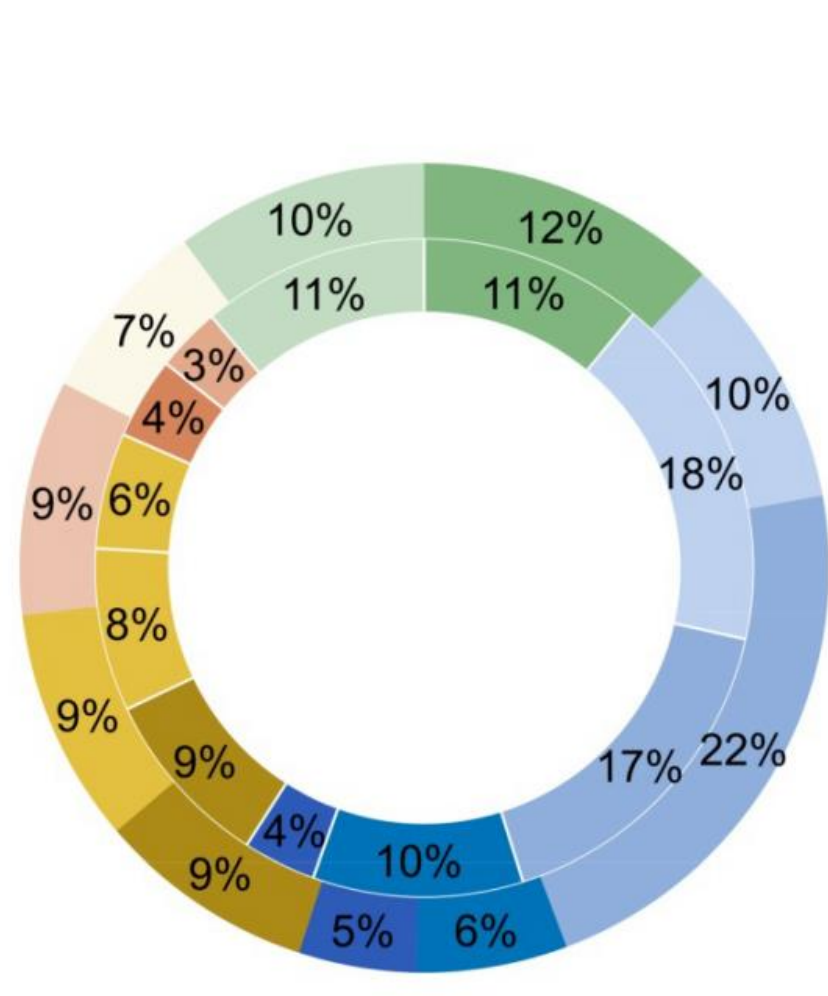

- Initial measurements

"Thermal cycling test, 200 cycles

= Damp heat test

- Humidity freeze test

- Thermal cycling test, 50 cycles

- Hot-spot endurance test

- Mechanical load test

= Mechanical load test (5400 Pa)

= Cut susceptibility test

= Bypass diode thermal test

Reverse current overload test

Light induced degradation

All other tests $(<3 \%)$

Figure 11: Distribution of failed tests for crystalline PV modules (inner ring) and of 370 IEC projects for thin-film PV modules (outer ring) between 2006 until June 2013. A test is considered a failure, if one or more PV modules will not pass the specific test. Figure extracted from ${ }^{[37]}$

\section{Practical value of stability studies and lifetime numbers}

\subsection{The advantage of comparability among different labs}

Reliable lifetime estimates are necessary for emerging photovoltaic technologies approaching the market. This means that, on one hand, protocols with high comparability for quantifying device stability must be established and applied between laboratories. On the other hand, environmental conditions for future applications must be clearly identified, so that relevant factors corresponding to performance loss under operational conditions can be mitigated. This is a complex challenge, as factors leading to performance loss over time are codependent, making it difficult to isolate singular mechanisms leading to device degradation and failure. The range of conditions under which stability studies are performed must be considered carefully when comparing lifetime estimates from different laboratories. 
The need to create awareness in the community about enhancing the comparability from stability studies has been well recognized by the OPV community with large coordinated efforts. ${ }^{[4-5,12 b, 82]}$ While these studies define relevant parameters for gauging stability and lifetime in organic photovoltaics, they also reveal that tests performed on the same device architectures in different laboratories under seemingly similar conditions can lead to vastly different estimations for performance lifetimes. This highlights the importance of recognizing and accounting for the cross-correlations between individual factors leading to age-induced performance loss.

\subsection{Accelerated aging: validity and limits}

In assessing the lifetimes of thin film solar cells there are no clear standards which define the conditions under which testing should occur. Solar cell lifetime is limited by a multitude of factors relating to the mechanical properties of the module, the structural stability of the active layer, the intrinsic chemical stability of the materials and interfaces and the degradation of materials and interfaces in the presence of ambient factors such as humidity and oxygen ${ }^{[83]}$ In order to identify key degradation and failure mechanisms and estimate device lifetimes, researchers will perform studies to differentiate between the stability of the component materials used to fabricate the solar cell (Durability) and the lifetime of the product as a whole, which is limited by individual component failures (Reliability). ${ }^{[67 b]}$ To this end, it is important to differentiate losses induced by extrinsic ambient factors and those resulting from intrinsic instabilities of materials and interfaces. ${ }^{[84]}$ Accelerated ageing tests are applied to identify and study the selected failure mechanisms by testing cells and modules under specified conditions. Common conditions applied in photovoltaics may include elevated temperature, repeated power cycling, increased humidity, extended irradiation and mechanical stress.

Accelerated ageing tests monitor the failure of specific components in the device, and extrapolate the lifetime by applying a model to predict performance loss over longer time 
scales. This approach strongly relies on the assumption that the decrease in performance is not influenced by additional factors, follows the predicted trend from the model, and that failure of other components in the device do not occur on a faster time scale than the effect being studied. Additionally device burn-in, which can vary strongly between device architectures, must be accurately accounted for in the data to minimize the error in lifetime estimates. ${ }^{[47 \mathrm{~b}]}$ In the case of encapsulated devices, barriers and sealing will increase device stability on the short term. On the longer term the complex behavior of oxygen and water permeation through barrier layer will occur, and lead to rapid degradation. This can lead to an overestimate of lifetimes if not accounted for. ${ }^{[85]}$

\subsection{Barriers and sealing: lag time versus equilibrium}

Generally, unencapsulated organic solar cells have lifetimes which are in the range of minutes to days. ${ }^{[45 \mathrm{a}, 47 \mathrm{a}]}$ The most common degradation pathways are rapid photo-oxidizing of the active layer when exposed to light and ambient oxygen ${ }^{[52,86]}$ and corrosion of the contact interfaces by oxidizing agents such as water vapor. ${ }^{[45 a, 68,87]}$ For perovskite solar cells, encapsulation is an important aspect, as well, as the photoactive materials, such as methylammonium lead iodide, hydrolyze in the presence of water, leading to a decomposition of the perovskite. ${ }^{[16]}$ While the ingress of water and oxygen can also activate certain degradation paths in the case of solid-state DSSCs, the leakage of electrolytes and evaporation of solvents out of the classical dye-sensitized cells also poses a large problem with respect to their stability, ${ }^{[27 a]}$ thus making proper sealing a necessity. In the field of organic light emitting diodes (OLEDs), it is generally accepted that a barrier must have a water vapor transmission rate (WVTR) of around $10^{-6} \mathrm{~g} \mathrm{~m}^{-2} \mathrm{day}^{-1}{ }^{[88]}$ Some studies have shown that some organic solar cells are less sensitive to water vapor than OLEDs, and WVTR which are 1000 times higher

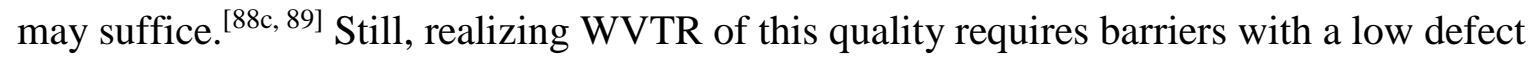
density, ${ }^{[88 b]}$ which can increase costs. 
The importance of barriers and sealing to prevent the penetration of ambient oxygen and water into the device has been widely recognized. In addition to protecting the solar cell, a good barrier should be transparent to allow light into the cell, flexible and light weight, and low cost.

One approach which is commonly applied to circumvent high cost is to apply multi-layer low cost barriers. This leads to an initial improvement in device stability due to retarded WVTR values. However, these initial WVTR are much lower than the equilibrium WTVR values associated with each layer of encapsulation. Graff et al. ${ }^{[88 \mathrm{~b}]}$ demonstrated the importance of considering lag, or breakthrough, time of water vapor in such multi-layer encapsulation structures. Initial WVTR values are lower due to the long diffusion rates of water vapor between different encapsulation layers, however once water vapor has permeated the encapsulation the WVTR suddenly rises. ${ }^{[90]}$ Over a longer time scale, multi-layer encapsulation strategies result in the same water permeation as single layers. This effect is shown by the schematic in Figure $12 .{ }^{[90]}$ While the multi-layer encapsulation introduces a long lag time, but at longer time scales the WVTR is the same in both structures. This effect was also demonstrated by Hermenau et al. ${ }^{[85]}$ while testing different encapsulation materials on small molecule solar cells. 


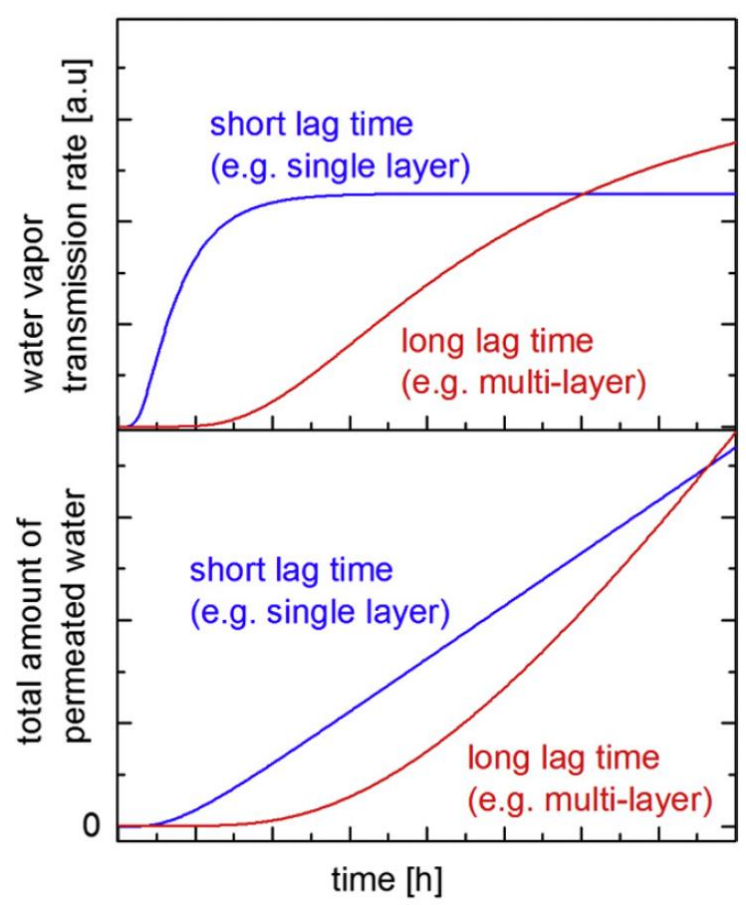

Figure 12: Schematic of water vapor transmission through a single layer (blue) and multi-layer (red) barrier. The top figure shows the WVTR and the bottom figure shows the total amount of water which permeates the barrier. Reproduced with permission from ${ }^{[90]}$.

For accurate lifetime estimates of encapsulated devices, a detailed understanding of the lag time for permeation of gases into the encapsulation is required, along with the equilibrium WVTR values of each layer of encapsulation.

\subsection{Cross-correlation between different lifetime values}

It is convenient to extrapolate specific lifetime values based on accelerated stress tests, however, care has to be taken when these values are used in the context of commercialization of the photovoltaic technology. After production, the photovoltaic device will first have an inactive rest period until sold and installed. The shelf lifetime and the operational lifetime cannot simply be combined to determine the application lifetime. This is specifically true if the sealing constitutes the limiting factor for lifetime, as the process of water and oxygen penetration will start right after the production. Generally, there will be variability in the history and storage times of devices once they reach the application stage, and thus the lag time through the barrier will influence the resulting application lifetime. This is an important point to consider when interpreting the results from accelerated aging tests. Furthermore and 
as pointed out above, the by accelerated testing determined operational lifetime cannot be simply transferred into an application lifetime when the lag time is considered as well Hence, precise knowledge about the dynamics of water and oxygen ingress has to be gained by sophisticated tests under controlled ambient conditions in order to correlate estimates for device stability under storage and application conditions. Furthermore, due to the humidity and temperature dependence of reactant ingress, the exact location and its climate will play an important role. Thus, the detailed specification of the barrier properties is mandatory to enable realistic lifetime predictions for specific application conditions.

\subsection{The significance of testing conditions for practical use: indoor versus outdoor}

One of the major advantages offered by organic and hybrid photovoltaics is the possibility to create flexible modules for novel applications not possible with conventional photovoltaic technologies. This point, however, makes it challenging to define the relevant operating conditions and therefore identify the stress factors which will play a role in determining the device lifetime. In the case of mobile applications, the light intensity and ambient conditions can vary considerably in the lifetime of a single module, and significant differences in operating conditions will also occur between modules depending on location and use. For example, the mechanical stress associated with daily handling and transporting, as well as irradiation is difficult to predict. The broad potential for application conditions therefore complicates the task of defining lifetime values further.

In the literature, stability testing on organic solar cells is primarily performed under simulated sunlight in indoor testing conditions and outdoor tests are less common. ${ }^{[89]}$ One of the Round Robin studies showed that the spectral distribution of the light sources used for illuminating the solar cells were a significant factor in determining device stability. ${ }^{[5]}$ In a later Round Robin study, outdoor testing was performed at different geographic locations. ${ }^{[82]}$ It was found that although the solar irradiation varies strongly between locations, there were less deviations in performance observed than in the indoor studies. This may also have to do with the 
optimized method developed for transporting the devices for the outdoor studies. However the results from the Round Robins demonstrate that there are still a number of open questions regarding which (combination of) parameters are significant in determining solar cell stability. The work done to date in the OPV community has been very successful in defining controlled conditions to perform stability testing. Equally important, the results of these large scale efforts have also revealed the complications involved in extrapolating accurate lifetime estimations.

\section{Conclusion}

Presently, a multitude of appropriate testing protocols exist, which were defined to better understand reliability, durability and stability as well as lifetime of thin-film photovoltaic devices. Specifically the OPV community spent the last few years establishing reliable and comparable testing protocols and stress parameters for determining device stability and extrapolating lifetimes. Many of the insights gained here will be valuable for more emerging technologies such as the field of perovskite photovoltaics, where reports on inconsistency in measurement results, stability and degradation indicate analogous issues regarding the requirement for comparability between laboratories. Hence, the points discussed in this review on the challenges involved in defining appropriate stability tests are expected to be relevant in a broader context. We distinguish between the aims and applicability of the IEC 61646 and ISOS protocols. Whereas the IEC 61646 was designed for certification of safety and reliability of a commercial product leading to qualification for entering the market, the ISOS-protocols constitute a useful collection of tests intended to improve the understanding of critical degradation effects in solar cells during their development phase, prior to commercialization. Furthermore, the ISOS protocols enabled a wide scale comparison of OPV lifetimes between different research labs, which lead to considerable progress in the field towards understanding and improving stability. Since development of the protocols, important 
issues relating to subtle differences in testing conditions between the labs have been identified.

These include the temperature of the device during testing and the light spectrum applied.

Hence the revelation of specifically these and few other potentially relevant testing parameters with high precision may further help to steepen the learning curve for improving the general stability of novel thin-film solar cells. For example, reporting also all photovoltaic parameters as a function of time instead of only the efficiency will lead to an accelerated knowledge gain about critical degradation pathways. The combination of diverse and welldefined testing conditions will reveal important information about acceleration factors, and application or storage dependent lifetimes, paving the way to reach technological maturity and readiness for the market. In conclusion, the extended ISOS-protocols will serve as an enabling step towards developing a photovoltaic technology, whereas the IEC tests will ultimately qualify a final product.

\section{Acknowledgements}

$\mathrm{RR}, \mathrm{TF}$ and $\mathrm{HH}$ are grateful for financial support by the German Federal Ministry of Education and Research in the framework of "AIMS in OPV", grant number 03EK3502. To the COST Action StableNextSol, MP1307. To MINECO for the xxx project.

R. Roesch and T. Faber contributed equally to this work.

Received: ((will be filled in by the editorial staff))

Revised: ((will be filled in by the editorial staff)) Published online: ((will be filled in by the editorial staff))

\section{ToC}

Common procedures and practices for evaluating thin-film solar cell stability and durability are reviewed with respect to their applicability for predicting failure routes and application lifetimes. Suggestions for reporting of detailed stress factors, photovoltaic parameters with sufficient statistical weight as well as new figures of merit are made with the goal of steepening the learning curve towards real applications.

Keyword: Solar Cells 
Roland Roesch, Tobias Faber, Elizabeth von Hauff, Thomas M. Brown, Monica Lira-Cantu, Harald Hoppe*

Title: Procedures and Practices for Evaluating Thin-Film Solar Cell Stability

\section{ToC figure}

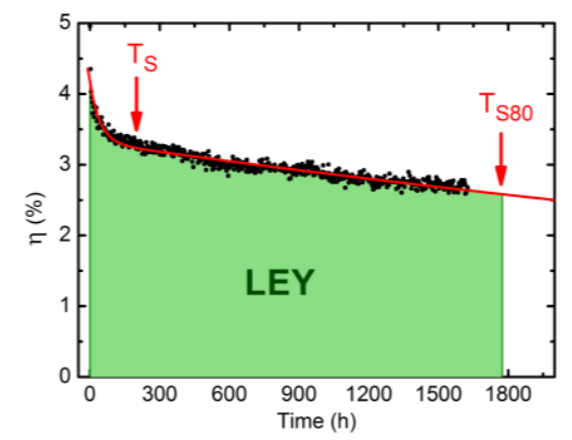

\section{References}

\section{[1] IEC 61646:2012-10 - “THIN-FILM TERRESTRIAL PHOTOVOLTAIC (PV)} MODULES DESIGN QUALIFICATION AND TYPE APPROVAL“ 2012.

[2] R. Arndt, R. Puto, Basic Understanding of IEC Standard Testing For Photovoltaic Panels, TÜV SÜD Product Service Report.

[3] a) Heliatek, http://www.easac.eu/fileadmin/docs/Low_Carbon/KVA_workshop/Renewables/2013_09_Eas ac_Stockholm_Leo.pdf; b) T. Y. Hirnori Arakawa, K. Okada, H. Masturi, T. Kitamura, N. Tanabe, Fujikura Technical Reviews 2009; c) Dyesol, http://www.pvtech.org/news/dyesol_claims_90_initial_performance_retention_after_extended_iec_61646_t es; d) R. B. C. B. Claudia Barolo, T. Brown, L. Bonandini, E. Busatto, S. Caramori, D. Colonna, G. De Angelis, A. Di Carlo, A. Guglielmotti, A. L. Andrea Guidobaldi, A. Lembo, D. Magistri, V. Mirruzzo, S. Penna, S. Pietrantoni, D. Prencipe, A. Reale, R. Riccitelli, A. Smarra, G. Soscia, R. Tagliaferro, L. Vesce, G. Viscardi and P. Mariani, Dyepower, proceeding of HOPV14 2014; e) Konarka, http://www1.eere.energy.gov/solar/pdfs/pvmrw12_poster_thinfilm_kam-lum.pdf.

[4] M. O. Reese, S. A. Gevorgyan, M. Jørgensen, E. Bundgaard, S. R. Kurtz, D. S. Ginley, D. C. Olson, M. T. Lloyd, P. Morvillo, E. A. Katz, A. Elschner, O. Haillant, T. R. Currier, V. Shrotriya, M. Hermenau, M. Riede, K. R. Kirov, G. Trimmel, T. Rath, O. Inganäs, F. Zhang, M. Andersson, K. Tvingstedt, M. Lira-Cantu, D. Laird, C. McGuiness, S. Gowrisanker, M. Pannone, M. Xiao, J. Hauch, R. Steim, D. M. DeLongchamp, R. Rösch, H. Hoppe, N. Espinosa, A. Urbina, G. Yaman-Uzunoglu, J.-B. Bonekamp, A. J. J. M. van Breemen, C. Girotto, E. Voroshazi, F. C. Krebs, Sol. Energy Mater. Sol. Cells 2011, 95, 1253.

[5] S. A. Gevorgyan, A. J. Medford, E. Bundgaard, S. B. Sapkota, H. F. Schleiermacher, B. Zimmermann, U. Wurfel, A. Chafiq, M. Lira-Cantu, T. Swonke, M. Wagner, C. J. Brabec, O. O. Haillant, E. Voroshazi, T. Aernouts, R. Steim, J. A. Hauch, A. Elschner, M. Pannone, M. Xiao, A. Langzettel, D. Laird, M. T. Lloyd, T. Rath, E. Maier, G. Trimmel, M. Hermenau, T. Menke, K. Leo, R. Rosch, M. Seeland, H. Hoppe, T. J. Nagle, K. B. Burke, C. J. Fell, D. Vak, T. B. Singh, S. E. Watkins, Y. Galagan, A. Manor, E. A. Katz, T. Kim, K. Kim, P. M. 
Sommeling, W. J. H. Verhees, S. C. Veenstra, M. Riede, M. G. Christoforo, T. Currier, V. Shrotriya, G. Schwartz, F. C. Krebs, Sol. Energy Mater. Sol. Cells 2011, 95, 1398.

[6] ASTM G173 - 03 - "Standard Tables for Reference Solar Spectral Irradiances: Direct Normal and Hemispherical on $37^{\circ}$ Tilted Surface" 2012.

[7] T. Faber, R. Roesch, K. R. Eberhardt, H. Hoppe, manuscript submitted 2015.

[8] G. Yu, C. Zhang, A. J. Heeger, Appl. Phys. Lett. 1994, 64, 1540.

[9] a) S. A. Gevorgyan, M. V. Madsen, H. F. Dam, M. Jørgensen, C. J. Fell, K. F. Anderson, B. C. Duck, A. Mescheloff, E. A. Katz, A. Elschner, R. Roesch, H. Hoppe, M. Hermenau, M. Riede, F. C. Krebs, Sol. Energy Mater. Sol. Cells 2013, 116, 187; b) D. Angmo, I. Gonzalez-Valls, S. Veenstra, W. Verhees, S. Sapkota, S. Schiefer, B. Zimmermann, Y. Galagan, J. Sweelssen, M. Lira-Cantu, R. Andriessen, J. M. Kroon, F. C. Krebs, Journal of Applied Polymer Science 2013, 130, 944.

[10] a) F. Livi, R. R. Sondergaard, T. R. Andersen, B. Roth, S. Gevorgyan, H. F. Dam, J. E. Carle, M. Helgesen, G. D. Spyropoulos, J. Adams, T. Ameri, C. J. Brabec, M. Legros, N. Lemaitre, S. Berny, O. R. Lozman, S. Schumann, A. Scheel, P. Apilo, M. Vilkman, E. Bundgaard, F. C. Krebs, Energy Technology 2015, 3, 423; b) F. C. Krebs, S. A. Gevorgyan, J. Alstrup, Journal of Materials Chemistry 2009, 19, 5442.

[11] M. Corazza, F. C. Krebs, S. A. Gevorgyan, Sol. Energy Mater. Sol. Cells 2014, 130, 99.

[12] a) G. Teran-Escobar, D. M. Tanenbaum, E. Voroshazi, M. Hermenau, K. Norrman, M. T. Lloyd, Y. Galagan, B. Zimmermann, M. Hosel, H. F. Dam, M. Jorgensen, S. Gevorgyan, S. Kudret, W. Maes, L. Lutsen, D. Vanderzande, U. Wurfel, R. Andriessen, R. Rosch, H. Hoppe, A. Rivaton, G. Y. Uzunoglu, D. Germack, B. Andreasen, M. V. Madsen, E. Bundgaard, F. C. Krebs, M. Lira-Cantu, Physical Chemistry Chemical Physics 2012, 14, 11824; b) D. M. Tanenbaum, M. Hermenau, E. Voroshazi, M. T. Lloyd, Y. Galagan, B. Zimmermann, M. Hosel, H. F. Dam, M. Jorgensen, S. A. Gevorgyan, S. Kudret, W. Maes, L. Lutsen, D. Vanderzande, U. Wurfel, R. Andriessen, R. Rosch, H. Hoppe, G. Teran-Escobar, M. LiraCantu, A. Rivaton, G. Y. Uzunoglu, D. Germack, B. Andreasen, M. V. Madsen, K. Norrman, F. C. Krebs, Rsc Advances 2012, 2, 882; c) R. Rosch, D. M. Tanenbaum, M. Jorgensen, M. Seeland, M. Barenklau, M. Hermenau, E. Voroshazi, M. T. Lloyd, Y. Galagan, B.

Zimmermann, U. Wurfel, M. Hosel, H. F. Dam, S. A. Gevorgyan, S. Kudret, W. Maes, L. Lutsen, D. Vanderzande, R. Andriessen, G. Teran-Escobar, M. Lira-Cantu, A. Rivaton, G. Y. Uzunoglu, D. Germack, B. Andreasen, M. V. Madsen, K. Norrman, H. Hoppe, F. C. Krebs, Energy Environ. Sci. 2012, 5, 6521; d) B. Andreasen, D. M. Tanenbaum, M. Hermenau, E. Voroshazi, M. T. Lloyd, Y. Galagan, B. Zimmernann, S. Kudret, W. Maes, L. Lutsen, D. Vanderzande, U. Wurfel, R. Andriessen, R. Rosch, H. Hoppe, G. Teran-Escobar, M. LiraCantu, A. Rivaton, G. Y. Uzunoglu, D. S. Germack, M. Hosel, H. F. Dam, M. Jorgensen, S. A. Gevorgyan, M. V. Madsen, E. Bundgaard, F. C. Krebs, K. Norrman, Physical Chemistry Chemical Physics 2012, 14, 11780.

[13] R. Po, A. Bernardi, A. Calabrese, C. Carbonera, G. Corso, A. Pellegrino, Energy Environ. Sci. 2014, 7, 925.

[14] H. Cao, W. He, Y. Mao, X. Lin, K. Ishikawa, J. H. Dickerson, W. P. Hess, Journal of Power Sources 2014, 264, 168.

[15] a) J. Burschka, N. Pellet, S.-J. Moon, R. Humphry-Baker, P. Gao, M. K. Nazeeruddin, M. Gratzel, Nature 2013, 499, 316; b) M. M. Lee, J. Teuscher, T. Miyasaka, T. N. Murakami, H. J. Snaith, Science 2012, 338, 643.

[16] G. D. Niu, X. D. Guo, L. D. Wang, J. Mater. Chem. A 2015, 3, 8970.

[17] a) Y. Han, S. Meyer, Y. Dkhissi, K. Weber, J. M. Pringle, U. Bach, L. Spiccia, Y.-B. Cheng, J. Mater. Chem. A 2015, 3, 8139; b) J. M. Frost, K. T. Butler, F. Brivio, C. H. Hendon, M. van Schilfgaarde, A. Walsh, Nano Letters 2014, 14, 2584. 
[18] N. J. Jeon, J. H. Noh, Y. C. Kim, W. S. Yang, S. Ryu, S. I. Seok, Nat Mater 2014, 13, 897.

[19] a) L. Zheng, Y.-H. Chung, Y. Ma, L. Zhang, L. Xiao, Z. Chen, S. Wang, B. Qu, Q. Gong, Chemical Communications 2014, 50, 11196; b) A. Mei, X. Li, L. Liu, Z. Ku, T. Liu, Y. Rong, M. Xu, M. Hu, J. Chen, Y. Yang, M. Grätzel, H. Han, Science 2014, 345, 295.

[20] F. Matteocci, S. Razza, F. Di Giacomo, S. Casaluci, G. Mincuzzi, T. M. Brown, A. D'Epifanio, S. Licoccia, A. Di Carlo, Physical Chemistry Chemical Physics 2014, 16, 3918.

[21] C. Law, L. Miseikis, S. Dimitrov, P. Shakya-Tuladhar, X. E. Li, P. R. F. Barnes, J. Durrant, B. C. O'Regan, Advanced Materials 2014, 26, 6268.

[22] A. Fakharuddin, F. Di Giacomo, I. Ahmed, Q. Wali, T. M. Brown, R. Jose, Journal of Power Sources 2015, 283, 61.

[23] a) M.-F. Xu, H. Zhang, S. Zhang, H. L. Zhu, H.-M. Su, J. Liu, K. S. Wong, L.-S. Liao, W. C. H. Choy, J. Mater. Chem. A 2015, 3, 14424; b) J. Xu, A. Buin, A. H. Ip, W. Li, O. Voznyy, R. Comin, M. Yuan, S. Jeon, Z. Ning, J. J. McDowell, P. Kanjanaboos, J.-P. Sun, X. Lan, L. N. Quan, D. H. Kim, I. G. Hill, P. Maksymovych, E. H. Sargent, Nat Commun 2015, 6; c) H. J. Snaith, A. Abate, J. M. Ball, G. E. Eperon, T. Leijtens, N. K. Noel, S. D. Stranks, J. T.-W. Wang, K. Wojciechowski, W. Zhang, The Journal of Physical Chemistry Letters 2014, 5, 1511; d) E. L. Unger, E. T. Hoke, C. D. Bailie, W. H. Nguyen, A. R. Bowring, T. Heumuller, M. G. Christoforo, M. D. McGehee, Energy Environ. Sci. 2014, 7, 3690; e) W. Tress, N. Marinova, T. Moehl, S. M. Zakeeruddin, M. K. Nazeeruddin, M. Gratzel, Energy Environ. Sci. 2015, 8, 995.

[24] X. Li, M. Tschumi, H. Han, S. S. Babkair, R. A. Alzubaydi, A. A. Ansari, S. S. Habib, M. K. Nazeeruddin, S. M. Zakeeruddin, M. Grätzel, Energy Technology 2015, 3, 551.

[25] K. Leo, Nat Nano 2015, 10, 574.

[26] B. O'Regan, M. Gratzel, Nature 1991, 353, 737.

[27] a) M. I. Asghar, K. Miettunen, J. Halme, P. Vahermaa, M. Toivola, K. Aitola, P. Lund, Energy Environ. Sci. 2010, 3, 418; b) R. Harikisun, H. Desilvestro, Solar Energy 2011, 85, 1179 ; c) A. Hinsch, J. M. Kroon, R. Kern, I. Uhlendorf, J. Holzbock, A. Meyer, J. Ferber, Progress in Photovoltaics: Research and Applications 2001, 9, 425; d) P. M. Sommeling, M. Späth, H. J. P. Smit, N. J. Bakker, J. M. Kroon, Journal of Photochemistry and Photobiology A: Chemistry 2004, 164, 137.

[28] S. Mastroianni, I. Asghar, K. Miettunen, J. Halme, A. Lanuti, T. M. Brown, P. Lund, Physical Chemistry Chemical Physics 2014, 16, 6092.

[29] K.-M. Lee, C.-Y. Chen, Y.-T. Tsai, L.-C. Lin, C.-G. Wu, RSC Advances 2013, 3, 9994.

[30] M. Marszalek, F. D. Arendse, J.-D. Decoppet, S. S. Babkair, A. A. Ansari, S. S. Habib, M. Wang, S. M. Zakeeruddin, M. Grätzel, Advanced Energy Materials 2014, 4, n/a.

[31] G. P. S. Lau, H. N. Tsao, C. Yi, S. M. Zakeeruddin, M. Grätzel, P. J. Dyson, ChemSusChem 2015, 8, 255.

[32] T. M. Brown, F. De Rossi, F. Di Giacomo, G. Mincuzzi, V. Zardetto, A. Reale, A. Di Carlo, J. Mater. Chem. A 2014, 2, 10788.

[33] a) P. Wang, S. M. Zakeeruddin, J. E. Moser, M. K. Nazeeruddin, T. Sekiguchi, M. Gratzel, Nat Mater 2003, 2, 402; b) H. J. Snaith, L. Schmidt-Mende, Advanced Materials 2007, 19, 3187; c) P. Wang, S. M. Zakeeruddin, P. Comte, I. Exnar, M. Grätzel, Journal of the American Chemical Society 2003, 125, 1166.

[34] R. Sastrawan, J. Renz, C. Prahl, J. Beier, A. Hinsch, R. Kern, Journal of Photochemistry and Photobiology A: Chemistry 2006, 178, 33.

[35] S. Mastroianni, A. Lanuti, T. M. Brown, R. Argazzi, S. Caramori, A. Reale, A. Di Carlo, Appl. Phys. Lett. 2012, 101, 123302.

[36] P. Robusto, "PV Module Tests from Safety Standards to Performance Checks", Solar Industry Magazine 2012. 
[37] Report IEA-PVPS T13-01 2014.

[38] D. C. Jordan, S. R. Kurtz, Progress in Photovoltaics: Research and Applications 2013, $21,12$.

[39] G. Makrides, B. Zinsser, M. Schubert, G. E. Georghiou, Solar Energy 2014, 103, 28.

[40] EU industrial initiative, https://setis.ec.europa.eu/implementation/technologyroadmap/european-industrial-initiative-on-solar-energy-photovoltaic-energy.

[41] a) J. Wolgemuth, S. Kurtz, 4th International PV Module QA Forum 2013; b) S. Kurtz, J. Wohlgemuth, T. Sample, M. Yamamichi, J. Amano, P. Hacke, M. Kempe, M. Kondo, T. Doi, K. Otani, 2011 37th IEEE Photovoltaic Specialists Conference (PVSC 2011) 2011, 000842.

[42] a) A. Skoczek, T. Sample, E. D. Dunlop, Progress in Photovoltaics 2009, 17, 227; b) O. S. Sastry, S. Saurabh, S. K. Shil, P. C. Pant, R. Kumar, A. Kumar, B. Bandopadhyay, Sol. Energy Mater. Sol. Cells 2010, 94, 1463; c) V. Sharma, S. S. Chandel, Renewable \& Sustainable Energy Reviews 2013, 27, 753.

[43] a) J. Wohlgemuth, IEC 61215: What it is and isn't, Presentation, NREL/PR-520054714, PV Module Reliability Workshop 2012; b) A. Zielnik, Validating Photovoltaic module durability tests, Solar America Board for Codes and Standards, technical report, www.solarabcs.org/durability, 2013.

[44] D. C. Jordan, S. R. Kurtz, 29th European PV Solar Energy Conference and Exhibition, Amsterdam, Netherlands 2014.

[45] a) M. Seeland, R. Roesch, H. Hoppe, Journal of Applied Physics 2011, 109; b) R. Roesch, M. Seeland, M. Baerenklau, G. Gobsch, H. Hoppe, Sol. Energy Mater. Sol. Cells 2013, 111, 212; c) P. Romero-Gomez, R. Betancur, A. Martinez-Otero, X. Elias, M. Mariano, B. Romero, B. Arredondo, R. Vergaz, J. Martorell, Sol. Energy Mater. Sol. Cells 2015, 137 , 44.

[46] E. Voroshazi, I. Cardinaletti, T. Conard, B. P. Rand, Advanced Energy Materials 2014, 4, n/a.

[47] a) R. Roesch, K. R. Eberhardt, S. Engmann, G. Gobsch, H. Hoppe, Sol. Energy Mater. Sol. Cells 2013, 117, 59; b) W. R. Mateker, I. T. Sachs-Quintana, G. F. Burkhard, R. Cheacharoen, M. D. McGehee, Chemistry of Materials 2015, 27, 404.

[48] F. C. Krebs, J. E. Carlé, N. Cruys-Bagger, M. Andersen, M. R. Lilliedal, M. A. Hammond, S. Hvidt, Sol. Energy Mater. Sol. Cells 2005, 86, 499.

[49] V. Turkovic, S. Engmann, N. Tsierkezos, H. Hoppe, U. Ritter, G. Gobsch, Acs Applied Materials \& Interfaces 2014, 6, 18525.

[50] C. H. Peters, I. T. Sachs-Quintana, W. R. Mateker, T. Heumueller, J. Rivnay, R. Noriega, Z. M. Beiley, E. T. Hoke, A. Salleo, M. D. McGehee, Advanced Materials 2012, 24, 663.

[51] H. Hintz, H. Peisert, H. J. Egelhaaf, T. Chasse, Journal of Physical Chemistry C 2011, $115,13373$.

[52] F. Deschler, A. De Sio, E. von Hauff, P. Kutka, T. Sauermann, H. J. Egelhaaf, J. Hauch, E. Da Como, Advanced Functional Materials 2012, 22, 1461.

[53] M. O. Reese, A. M. Nardes, B. L. Rupert, R. E. Larsen, D. C. Olson, M. T. Lloyd, S. E. Shaheen, D. S. Ginley, G. Rumbles, N. Kopidakis, Advanced Functional Materials 2010, 20, 3476.

[54] T. Heumueller, W. R. Mateker, I. T. Sachs-Quintana, K. Vandewal, J. A. Bartelt, T. M. Burke, T. Ameri, C. J. Brabec, M. D. McGehee, Energy Environ. Sci. 2014, 7, 2974.

[55] a) O. Synooka, K. R. Eberhardt, C. R. Singh, F. Hermann, G. Ecke, B. Ecker, E. von Hauff, G. Gobsch, H. Hoppe, Advanced Energy Materials 2014, 4, 1300981 (10 pp.); b) I. T. Sachs-Quintana, T. Heumuller, W. R. Mateker, D. E. Orozco, R. Cheacharoen, S. Sweetnam, C. J. Brabec, M. D. McGehee, Advanced Functional Materials 2014, 24, 3978. 
[56] B. C. Schroeder, Z. Li, M. A. Brady, G. C. Faria, R. S. Ashraf, C. J. Takacs, J. S. Cowart, D. T. Duong, K. H. Chiu, C. H. Tan, J. T. Cabral, A. Salleo, M. L. Chabinyc, J. R. Durrant, I. McCulloch, Angewandte Chemie-International Edition 2014, 53, 12870.

[57] J. Kong, S. Song, M. Yoo, G. Y. Lee, O. Kwon, J. K. Park, H. Back, G. Kim, S. H. Lee, H. Suh, K. Lee, Nature Communications 2014, 5.

[58] Z. M. Beiley, C. H. Peters, I. T. Sachs-Quitana, E. T. Hoke, G. F. Burkhard, M. D. McGehee, 2011 37th IEEE Photovoltaic Specialists Conference (PVSC 2011) 2011, 003683.

[59] J. Kesters, P. Verstappen, J. Raymakers, W. Vanormelingen, J. Drijkoningen, J. D'Haen, J. Manca, L. Lutsen, D. Vanderzande, W. Maes, Chemistry of Materials 2015, 27, 1332.

[60] B. Zimmermann, U. Würfel, M. Niggemann, Sol. Energy Mater. Sol. Cells 2009, 93, 491.

[61] a) M. Jørgensen, K. Norrman, F. C. Krebs, Sol. Energy Mater. Sol. Cells 2008, 92, 686; b) M. Jørgensen, K. Norrman, S. A. Gevorgyan, T. Tromholt, B. Andreasen, F. C. Krebs, Advanced Materials 2012, 24, 580; c) V. Turkovic, S. Engmann, D. A. M. Egbe, M.

Himmerlich, S. Krischok, G. Gobsch, H. Hoppe, Sol. Energy Mater. Sol. Cells 2014, 120, 654. [62] a) H. Neugebauer, C. Brabec, J. C. Hummelen, N. S. Sariciftci, Sol. Energy Mater. Sol. Cells 2000, 61, 35; b) M. V. Madsen, K. Norrman, F. C. Krebs, Journal of Photonics for Energy 2011, 1, 011104; c) K. Norrman, M. V. Madsen, S. A. Gevorgyan, F. C. Krebs, Journal of the American Chemical Society 2010, 132, 16883.

[63] a) A. Kumar, R. Devine, C. Mayberry, B. Lei, G. Li, Y. Yang, Advanced Functional Materials 2010, 20, 2729; b) A. Rivaton, S. Chambon, M. Manceau, J.-L. Gardette, N.

Lemaître, S. Guillerez, Polymer Degradation and Stability 2010, 95, 278.

[64] G. Teran-Escobar, J. Pampel, J. M. Caicedo, M. Lira-Cantu, Energy Environ. Sci. 2013, 6, 3088 .

[65] a) E. A. Katz, A. Manor, A. Mescheloff, T. Tromholt, F. C. Krebs, 2012 IEEE 38th Photovoltaic Specialists Conference (PVSC) 2012, 003249; b) I. Visoly-Fisher, A.

Mescheloff, M. Gabay, C. Bounioux, L. Zeiri, M. Sansotera, A. E. Goryachev, A. Braun, Y. Galagan, E. A. Katz, Sol. Energy Mater. Sol. Cells 2015, 134, 99.

[66] a) S. Bertho, G. Janssen, T. J. Cleij, B. Conings, W. Moons, A. Gadisa, J. D’Haen, E. Goovaerts, L. Lutsen, J. Manca, D. Vanderzande, Sol. Energy Mater. Sol. Cells 2008, 92, 753; b) S. Bertho, I. Haeldermans, A. Swinnen, W. Moons, T. Martens, L. Lutsen, D. Vanderzande, J. Manca, A. Senes, A. Bonfiglio, Sol. Energy Mater. Sol. Cells 2007, 91, 385; c) M. Tessarolo, A. Guerrero, D. Gedefaw, M. Bolognesi, M. Prosa, X. Xu, M. Mansour, E. Wang, M. Seri, M. R. Andersson, M. Muccini, G. Garcia-Belmonte, Sol. Energy Mater. Sol. Cells 2015, 141, 240.

[67] a) S. Schuller, P. Schilinsky, J. Hauch, C. J. Brabec, Applied Physics a-Materials Science \& Processing 2004, 79, 37; b) O. Haillant, Sol. Energy Mater. Sol. Cells 2011, 95, 1284; c) O. Haillant, D. Dumbleton, A. Zielnik, Sol. Energy Mater. Sol. Cells 2011, 95, 1889. [68] B. Ecker, J. C. Nolasco, J. Pallares, L. F. Marsal, J. Posdorfer, J. Parisi, E. von Hauff, Advanced Functional Materials 2011, 21, 2705.

[69] M. Manceau, E. Bundgaard, J. E. Carle, O. Hagemann, M. Helgesen, R. Sondergaard, M. Jorgensen, F. C. Krebs, Journal of Materials Chemistry 2011, 21, 4132.

[70] G. Wantz, L. Derue, O. Dautel, A. Rivaton, P. Hudhomme, C. Dagron-Lartigau, Polymer International 2014, 63, 1346.

[71] E. Bundgaard, M. Helgesen, J. E. Carlé, F. C. Krebs, M. Jørgensen, Macromolecular Chemistry and Physics 2013, 214, 1546.

[72] M. Drees, H. Hoppe, C. Winder, H. Neugebauer, N. S. Sariciftci, W. Schwinger, F. Schaffler, C. Topf, M. C. Scharber, Z. G. Zhu, R. Gaudiana, Journal of Materials Chemistry 2005, 15, 5158. 
[73] EU, http://ec.europa.eu/enterprise/policies/raw-materials/files/docs/crm-report-oncritical-raw-materials_en.pdf.

[74] M. Hermenau, M. Riede, K. Leo, S. A. Gevorgyan, F. C. Krebs, K. Norrman, Sol. Energy Mater. Sol. Cells 2011, 95, 1268.

[75] a) Y. Sahin, S. Alem, R. de Bettignies, J. M. Nunzi, Thin Solid Films 2005, 476, 340;

b) M. S. White, D. C. Olson, S. E. Shaheen, N. Kopidakis, D. S. Ginley, Appl. Phys. Lett. 2006, 89.

[76] Y. Udum, P. Denk, G. Adam, D. H. Apaydin, A. Nevosad, C. Teichert, M. S. White, N. S. Sariciftci, M. C. Scharber, Organic Electronics 2014, 15, 997.

[77] B. Ecker, J. Posdorfer, E. von Hauff, Sol. Energy Mater. Sol. Cells 2013, 116, 176.

[78] a) K. Lee, J. Y. Kim, S. H. Park, S. H. Kim, S. Cho, A. J. Heeger, Advanced Materials 2007, 19, 2445; b) A. Hayakawa, O. Yoshikawa, T. Fujieda, K. Uehara, S. Yoshikawaa, Appl. Phys. Lett. 2007, 90; c) D. H. Wang, S. H. Im, H. K. Lee, O. O. Park, J. H. Park, Journal of Physical Chemistry C 2009, 113, 17268; d) J. H. Lee, S. Cho, A. Roy, H. T. Jung, A. J. Heeger, Appl. Phys. Lett. 2010, 96; e) E. Voroshazi, B. Verreet, A. Buri, R. Müller, D. Di Nuzzo, P. Heremans, Organic Electronics 2011, 12, 736; f) Z. George, E. Voroshazi, C. Lindqvist, R. Kroon, W. Zhuang, E. Wang, P. Henriksson, A. Hadipour, M. R. Andersson, Sol. Energy Mater. Sol. Cells 2015, 133, 99.

[79] a) C. R. Osterwald, 2008; b) A. Schlumberger, "Right down to the last electron", Photon International 2006.

[80] a) F. De Rossi, T. Pontecorvo, T. M. Brown, manuscript submitted 2015; b) G24 Power Ltd. http://gcell.com 2015; c) Ricoh Ltd. Complete Solid-State Dye-Sensitized Solar Cell, http://www.ricoh.com/about/company/technology/tech/066_dssc.html 2014.

[81] a) J. Wohlgemuth, BP Solar, Overview of Failure Mechanisms and PV Qualification Tests, Presentation, PV Module Reliaibility Workshop 2010; b) UL report, Achieving Increased Reliability in Photovoltaic Installations, http://library.ul.com/wpcontent/uploads/sites/40/2015/02/UL_Final_Achieving-Increased-Reliability-in-PhotovoltaicInstallations_v8-HR.pdf; c) U. Jahn, TUV Rheinland Group, Presentation, PV MODULE RELIABILITY ISSUES INCLUDING TESTING AND CERTIFICATION 27th EUPVSEC 2012; d) F. Roca, G. Graditi, presentation, RELIABILITY ISSUE OF PHOTOVOLTAIC DEVICES AND SYSTEMS, ESREF 2010.

[82] M. V. Madsen, S. A. Gevorgyan, R. Pacios, J. Ajuria, I. Etxebarria, J. Kettle, N. D. Bristow, M. Neophytou, S. A. Choulis, L. S. Roman, T. Yohannes, A. Cester, P. Cheng, X. W. Zhan, J. Wu, Z. Y. Xie, W. C. Tu, J. H. He, C. J. Fell, K. Anderson, M. Hermenau, D. Bartesaghi, L. J. A. Koster, F. Machui, I. Gonzalez-Valls, M. Lira-Cantu, P. P. Khlyabich, B. C. Thompson, R. Gupta, K. Shanmugam, G. U. Kulkarni, Y. Galagan, A. Urbina, J. Abad, R. Roesch, H. Hoppe, P. Morvillo, E. Bobeico, E. Panaitescu, L. Menon, Q. Luo, Z. W. Wu, C. Q. Ma, A. Hambarian, V. Melikyan, M. Hambsch, P. L. Burn, P. Meredith, T. Rath, S. Dunst, G. Trimmel, G. Bardizza, H. Mullejans, A. E. Goryachev, R. K. Misra, E. A. Katz, K. Takagi, S. Magaino, H. Saito, D. Aoki, P. M. Sommeling, J. M. Kroon, T. Vangerven, J. Manca, J. Kesters, W. Maes, O. D. Bobkova, V. A. Trukhanov, D. Y. Paraschuk, F. A. Castro, J. Blakesley, S. M. Tuladhar, J. A. Rohr, J. Nelson, J. B. Xia, E. A. Parlak, T. A. Tumay, H. J. Egelhaaf, D. M. Tanenbaum, G. M. Ferguson, R. Carpenter, H. Z. Chen, B. Zimmermann, L. Hirsch, G. Wantz, Z. Q. Sun, P. Singh, C. Bapat, T. Offermans, F. C. Krebs, Sol. Energy Mater. Sol. Cells 2014, 130, 281.

[83] C. J. Brabec, S. Gowrisanker, J. J. M. Halls, D. Laird, S. J. Jia, S. P. Williams, Advanced Materials 2010, 22, 3839.

[84] I. Cardinaletti, J. Kesters, S. Bertho, B. Conings, F. Piersimoni, J. D'Haen, L. Lutsen, M. Nesladek, B. Van Mele, G. Van Assche, K. Vandewal, A. Salleo, D. Vanderzande, W. Maes, J. V. Manca, Journal of Photonics for Energy 2014, 4. 
[85] M. Hermenau, S. Schubert, H. Klumbies, J. Fahlteich, L. Muller-Meskamp, K. Leo, M. Riede, Sol. Energy Mater. Sol. Cells 2012, 97, 102.

[86] J. Razzell-Hollis, J. Wade, W. C. Tsoi, Y. Soon, J. Durrant, J. S. Kim, J. Mater. Chem. A 2014, 2, 20189.

[87] E. Voroshazi, B. Verreet, T. Aernouts, P. Heremans, Sol. Energy Mater. Sol. Cells 2011, 95, 1303.

[88] a) M. S. Weaver, L. A. Michalski, K. Rajan, M. A. Rothman, J. A. Silvernail, J. J. Brown, P. E. Burrows, G. L. Graff, M. E. Gross, P. M. Martin, M. Hall, E. Mast, C. Bonham, W. Bennett, M. Zumhoff, Appl. Phys. Lett. 2002, 81, 2929; b) G. L. Graff, R. E. Williford, P. E. Burrows, Journal of Applied Physics 2004, 96, 1840; c) S. Cros, R. de Bettignies, S.

Berson, S. Bailly, P. Maisse, N. Lemaitre, S. Guillerez, Sol. Energy Mater. Sol. Cells 2011, 95, S65.

[89] J. A. Hauch, P. Schilinsky, S. A. Choulis, R. Childers, M. Biele, C. J. Brabec, Sol. Energy Mater. Sol. Cells 2008, 92, 727.

[90] G. Nisato, H. Klumbies, J. Fahlteich, L. Muller-Meskamp, P. van de Weijer, P. Bouten, C. Boeffel, D. Leunberger, W. Graehlert, S. Edge, S. Cros, P. Brewer, E. Kucukpinar, J. de Girolamo, P. Srinivasan, Organic Electronics 2014, 15, 3746. 